\title{
1 Molecular Basis of Urostyle Development: Genes and Gene 2 Regulation Underlying an Evolutionary Novelty
}

3

4 Gayani Senevirathne ${ }^{1,2, *}$ and Neil H. Shubin ${ }^{1^{*}}$

6 Affiliations:

$7 \quad{ }^{1}$ Department of Organismal Biology \& Anatomy, University of Chicago, Chicago, IL 60615

$8 \quad{ }^{2}$ Department of Human Evolutionary Biology, Harvard University, Cambridge, MA 02138

9

*Corresponding author email addresses: msenevirathne@,fas.harvard.edu nshubin@uchicago.edu

Keywords: Hypochord, T-box genes, RNA-seq, ATAC-seq, metamorphosis 
AbSTRACT (200 words)

Evolutionary novelties entail the origin of morphologies that enable new functions.

18 These features can arise through changes to gene function and regulation. One important novelty

19 is the fused rod at the end of the vertebral column in anurans, the urostyle. This feature is

20 composed of a coccyx and an ossifying hypochord, and both structures ossify during

21 metamorphosis. We used Laser Capture Micro-dissection of these identified tissues and

22 subjected them to RNA-seq and ATAC-seq analyses at three developmental stages in tadpoles of

23 Xenopus tropicalis. These experiments reveal that the coccyx and hypochord have two different

24 molecular signatures. ATAC-seq data reveals potential regulatory regions that are observed in

25 proximity to candidate genes identified from RNA-seq. Neuronal (TUBB3) and muscle markers

$26(M Y H 3)$ are upregulated in coccygeal tissues, whereas T-box genes (TBXT, TBXT.2),

27 corticosteroid stress hormones (CRCH.1), and matrix metallopeptidases (MMP1, MMP8,

28 MMP13) are upregulated in the hypochord. Even though an ossifying hypochord is only present

29 in anurans, this ossification between the vertebral column and the notochord appears to resemble

30 a congenital vertebral anomaly seen prenatally in humans, caused by an ectopic expression of the

$31 T B X T / T B X T .2$ gene. This work opens the way to functional studies that help us better elucidate

32 anuran bauplan evolution. 
Phenotypic and genotypic changes from an existing ancestral condition undergird the evolution of "key innovations" (Galis and Metz 2007). Phenotypic changes of a novel structure reflect changes in the corresponding genotypic/gene regulatory networks (Shubin, Tabin, and

37 Carroll 2009; Tarazona et al. 2016; Tschopp and Tabin 2017; Wagner 2015). Previous studies have highlighted that the anuran (frog and toad) urostyle, composed of a coccyx and a

39 hypochord, is morphologically unique from the rest of the vertebrates because of the contribution

40 of an ossifying hypochord, and is therefore considered a structural novelty (Senevirathne et al.

41 2020; Handrigan and Wassersug 2007; Branham and List 1979; Kovalenko and Anisimova 1987;

42 Kovalenko and Danilov 2006; Snell 2015). The coccyx, which is derived from the paraxial

43 mesoderm, gives rise to the caudal vertebrae (Handrigan and Wassersug 2007; Sanchez and

44 Sanchez 2013, 2015), which subsequently undergo endochondral ossification and fuse together

45 during metamorphosis (Senevirathne et al. 2020). The amphibian hypochord, thought to be

46 derived from either endoderm (Cleaver and Krieg 1998; Cleaver, Seufert, and Krieg 2000;

47 Lofberg and Collazo 1997) or superficial mesoderm (Shook, Majer, and Keller 2004), is a thin

48 embryonic rod, which degenerates in the rest of anamniotes during early embryonic

49 development, but is retained only in frogs and undergoes endochondral ossification during the 50 metamorphic climax (Handrigan and Wassersug 2007; Branham and List 1979; Kovalenko and

51 Anisimova 1987; Kovalenko and Danilov 2006; Senevirathne et al. 2020; Snell 2015).

52 The ossifying hypochord, an apomorphic structure in anurans, occludes the dorsal aorta 53 and is hypothesized to aid in rapid tail resorption (Senevirathne et al. 2020). We highlighted the 
54 phenotypic changes associated with the evolution of this structure in anurans and discussed how

55 bones and cartilage, muscles, neurons form, and proposed how the hypochordal ossification has a

56 role in the evolution of the anuran bauplan (Senevirathne et al. 2020). Despite being derived

57 from two different populations of cells, both coccyx and hypochord undergo endochondral

58 ossification during metamorphosis. Undifferentiated mesenchymal cells of the coccyx and

59 embryonic hypochordal cells chondrify and ossify when the tadpole locomotion changes from an

60 axial-driven mode to a limb-driven one. Ossification of the hypochord is rapid, usually ranging

61 from 6-8 days. Apart from the cartilage and bone formation, the neuro-muscular skeleton is also

62 remodeled. The muscles near the future caudo-pelvic region of the tadpole are remodeled during

63 metamorphosis. The primary myotomes (Dorsalis trunci) remodel to form three different types of

64 muscles (Longissimus dorsi, Coccygeoiliacus, Coccygeosacralis), where all three muscles attach

65 to the coccyx. The axial motor neurons in the tail degenerate, and, at the same time, the spinal

66 cord degenerates with the fusion of the coccyx and hypochord (Senevirathne et al. 2020).

68 dorsal aorta, and the hypochord degenerates (except in anurans) after serving its purpose.

69 Surprisingly, in mature tadpoles, CT scanning data revealed a possible role of the ossifying

70 hypochord in remodeling the dorsal aorta as well. The posterior-most end of the hypochord

71 appears to occlude the dorsal aorta, which could aid the rapid tail loss by cutting the blood

72 supply to the tail (Senevirathne et al. 2020). Hence, we speculated that the ossifying hypochord

73 has a role in the evolution of the anuran bauplan, and this could be a reason why it has been 
74 evolutionary favored in anurans for more than 200 million years (Shubin, Tabin, and Carroll 2009; Shubin and Jenkins 1995).

The phenotypic changes of the urostyle are well studied (Branham and List 1979;

Kovalenko and Danilov 2006; Senevirathne et al. 2020); however, the molecular mechanisms underlying this unique structure have remained obscure to-date. Here, we investigate transcriptomic and gene regulatory networks in the developing urostyle by combining RNA-seq and ATAC-seq approaches. Using our previous morphology work (Senevirathne et al., 2020) as a framework to identify targeted cells, we used Laser Capture Microdissection to reveal the transcriptomics and epigenomics of the two tissue types, coccyx and hypochord.

Mesenchymal cells in vertebrates that undergo ossification have a conserved transcriptomic signature. Vertebrate ossification can be either endochondral or intramembranous, and a compendium of genes, transcription factors, intrinsic and external cues control ossification. During this process mesenchymal cells initially condense and commit to form osteoprogenitors (genes like $S O X 2, R U N X 2$ are involved in this). Next, the osteoprogenitors differentiate to form preosteoblasts and osteoblasts (BMPs, FGFs, TGFß, and Wntß/catenin are involved in this (e.g., (Horowitz 2003; Karsenty 2008; Shen et al. 2014; Sodek and McKee 2000; Stein et al. 2003), and finally, mineralization and apoptosis of osteoblasts form mature osteocytes (e.g., (Horowitz 2003; Karsenty 2008; Shen et al. 2014; Sodek and McKee 2000; Stein et al. 2003). Paraxial mesoderm-derived coccygeal cells are undifferentiated mesenchymal cells; they undergo chondrification and ossification prior to the initiation of the metamorphic climax 
95 regulatory network as connective tissues and bones in vertebrates. However, the ossifying

96 hypochord initiates ossification at the onset of metamorphosis. The origin of amphibian

97 hypochordal cells has been hypothesized to be from the endoderm (Cleaver and Krieg 1998;

98 Cleaver, Seufert, and Krieg 2000; Lofberg and Collazo 1997), or the superficial mesoderm

99 (Shook, Majer, and Keller 2004). Regardless of which germ layer it is derived from, hypochord

100 undergoes endochondral ossification only in anurans. But the genes and gene regulatory regions

101 that control the development of this structural enigma remain unknown. Here, we compare the

102 gene expression patterns of coccygeal and hypochordal cells to identify similar/different

103 pathways between the two tissue types, which are derived from two different cell populations.

104 Through this work, we address the following questions: Why does the hypochord only

105 ossify in anurans? What are the similarities/differences between the hypochordal and coccygeal

106 molecular pathways? Which genes switch on/off during metamorphosis? By identifying the

107 underlying changes in the genes and gene regulatory networks, our work begins to shed light on

108 the potential genotypic changes underlying a structural novelty.

\section{MATERIALS AND METHODS}

110 Different stages of Xenopus tropicalis tadpoles were purchased from the National Xenopus

111 Resource (NXR) at the Marine Biological Laboratory (MBL), Woods Hole, MA. Comparisons

112 were made across three significant life-history stages to highlight the differences/similarities of

113 genes and gene regulatory dynamics during metamorphosis. The developmental stages used for

114 the experiments were as follows: before metamorphosis/prometamorphic stages (stage 56/57), at 
115 the beginning of the metamorphic climax (stage 60/61), and end of metamorphosis (stage 65/66).

116 The tadpoles were euthanized using $0.2 \%$ aqueous tricaine methanesulfonate (MS-222), and the

117 specimens were fixed in different fixatives or fresh tissues were taken according to each

118 experiment. Tadpoles were staged according to Nieuwkoop and Faber (NF). The codes generated

119 for the bioinformatics analyses are deposited in GitHub

120 (https://github.com/GayaniSenevirathne/Senevirathne et al_RNAseq.git) and the raw sequences

121 are available at NCBI (Accession numbers will be given upon acceptance).

123 RNA-seq using spatial transcriptomics and Laser microdissection (LCM)

124 Xenopus tropicalis tadpoles at prometamorphosis (stage 56), beginning of the metamorphic

125 climax (stage 60/61) and end of metamorphosis (stage 65/66) were selected as the targeted stages

126 for the RNA-seq experiment (stages were selected based on the significant phenotypic changes

127 that were seen at each stage during the urostyle development based on Senevirathne et al., 2020).

128 All forceps, scissors, surgical blades and lab benches were cleaned with RNAse away and $100 \%$

129 ethanol prior to any RNA sequencing experiment. Tadpoles were euthanized using MS-222. The

130 region where the urostyle forms (demarcated by the tenth and fourteenth myotomes;

131 Senevirathne et al., 2020) was dissected under a Leica L2 light microscope on ice-cold 1x

132 DEPC-treated PBS; all the dissections were done on ice to prevent RNA degradation. The

133 dissected tissue was immediately transferred to ice-cold OCT and flash frozen in liquid nitrogen

134 and stored at $-80^{\circ} \mathrm{C}$ (for better RNA quality, the tissue blocks were processed the subsequent

135 day). The frozen tissue blocks were sectioned using a Leica cryostat. 
136 To carry out a transcriptomic survey during urostyle development, we adapted a spatial

137 transcriptomic approach (using Laser capture microdissection). The two targeted tissue types,

138 coccyx and hypochord, from three individuals at each developmental stage (prometamorphosis,

139 beginning of metamorphic climax, and end of metamorphosis) were dissected from frozen

140 sections (Fig. 1A). The myotomic boundaries were used as a way of identifying the targeted area

141 to be dissected out. Cells of interest were identified based on Senevirathne et al (Senevirathne et

142 al., (2020)). Prometamorphic (stage 56) sections of coccyx had undifferentiated mesenchymal

143 cells around the spinal cord, and the hypochord had embryonic hypochordal cells ventral to the

144 notochord. The RNA-sequencing protocol followed a spatial transcriptomics method (Geo-seq;

145 (Chen et al. 2017)). Prior to sectioning, the cryostat, brushes, adjacent benches/tabletops, blades,

146 and pencils/pens were cleaned using RNAse away and 100\% ethanol. The tissue blocks were left

147 inside the cryostat for 20 minutes, allowing them to equilibrate at $-20^{\circ} \mathrm{C}$ (not doing this resulted

148 in flaky sections or sections breaking when transferred onto the slides). The tissues were

149 sectioned at $16 \mu \mathrm{M}$ thickness on to PEN membrane 1.0 slides. Five-six sections were placed on

150 each slide and were allowed to dry at room temperature for one minute before storing them at -

$15180^{\circ} \mathrm{C}$ for further processing (samples that were $<1$ month old were used for sectioning; the yield

152 of RNA was high when the slides were sectioned on the same day).

153 On the day of the Laser capture microdissection, slides were removed from the freezer,

154 thawed at room temperature for 2 minutes, and placed under an UV lamp for 2 minutes (UV

155 helps the sections to adhere to the slide). Next, the slides were stained using Cresyl Violet to help

156 visualize the cells. For this, slides were taken along an ethanol series, each wash was 30 seconds 
157 each (100\% ethanol, $70 \%$ ethanol, Cresyl Violet in $70 \%$ ethanol, and were dehydrated in $70 \%$,

$15890 \%$, and $100 \%$ ethanol). Slides were allowed to dry completely before moving to the next steps

159 (this step was important to avoid humidity affecting the RNA quality (Ordway et al. 2009).

The dehydrated slides were processed via LCM with the following settings: aperture (10),

161 speed (20) and energy (50). The hypochordal and coccygeal cells were identified (histological

162 comparisons done in Senevirathne et al. (Senevirathne et al. 2020) were used as a reference)

163 using the $\mathrm{x} 10$ eye piece and the dissections were done using the $\mathrm{x} 20$. Targeted cells were

164 captured to an adhesive cap Eppendorf tube, with the cap consisting of $50 \mathrm{ul}$ of the lysis buffer.

165 Once the cells from coccyx and hypochord were collected $(\sim 10,000$ cells from 10 sections for

166 each tissue type, 4 replicates were done for each stage, a total of 24 samples), 150ul of the lysis

167 buffer was added to each tube and was left on ice for 20 minutes. RNA was extracted from the

168 captured cells using the TAKARA NucleoSpin ${ }^{\circledR}$ RNA XS (Cat. No. 740902) kit with slight

169 modifications (the filtration step was skipped). cDNA was generated using the SMART-Seq® v4

170 Ultra ${ }^{\circledR}$ Low Input RNA Kit for Sequencing (with the number of amplification cycles set to 18).

171 cDNA was purified using Agencourt Ampure XP magnetic beads (Beckman Coulter) and were

172 sequenced using the HiSeq PE100.

\section{Gene regulation and ATAC-seq}

175 The same developmental stages that were used for the RNA-seq studies were taken, and the

176 urostyle region was dissected out as a fresh chunk of tissue (morphological demarcations of the

177 developing urostyle were decided based on Senevirathne et al. (Senevirathne et al. 2020)). The 
178 OMNI-ATAC-seq protocol was used to identify open chromatin regions in the developing 179 urostyle (two replicates from each developmental stage, coinciding with the RNA-seq and 180 morphological studies, were selected).

The tadpoles were anesthetized in MS-222, dissected on ice-cold 1X PBS and were

182 mechanically crushed using a pestle (cleaned using $100 \%$ ethanol prior to this step) to obtain a

183 homogenized sample (all these steps were done on ice to prevent degradation of proteins). Once

184 a homogenized sample was obtained, cells were counted using the BioRad Tc20 automated cell

185 counter. All samples consisted of 75,000-100,000 cells. The subsequent steps followed the

186 OMNI-ATAC seq protocol (Buenrostro et al. 2015; Corces et al. 2017) with slight modifications

187 using the Illumina Tagment DNA Enzyme and Buffer kit: cells were lysed in an ice-cold lysis

188 buffer, followed by a transposition step using Tn5 Transposase, and DNA was purified using the

189 Zymo DNA Clean and Concentrator. Purified DNA was amplified with 13 amplification cycles

190 (the number of cycles were optimized by an additional qPCR step). Finally, the libraries were

191 purified using the Zymo DNA Clean and Concentrator and were sequenced using the NovaSeq

1922000 (100BP PE).

\section{RNA-seq analyses}

195 Three stages were targeted for all the next-generation sequencing steps - Before metamorphosis

196 (stage 56/57), beginning of metamorphosis (stage 60/61), and end of metamorphosis (stage

197 65/66). RNA from two different regions, coccyx and the hypochord, was extracted from three 
198 individuals for each stage (18 samples). 9 samples were run per lane, using paired end $100 \mathrm{bp}$

199 reads on a llumina HiSeq 2000, at the Genomic core at the University of Chicago.

202 genome v. 9.1 (Xenopus_tropicalis_v9.1.dna.toplevel.fa.gz) and transcript annotations were

203 downloaded from Ensembl (www. Ensembl.org). Adapter sequences were trimmed using

204 Cutadapt (version 1.8.1). Trimmed sequences were mapped using two approaches to compare the

205 differentially expressed genes: 1. Normal alignment using HTSeq v.0.13.5 (Anders, Pyl, and

206 Huber 2015) and Bowtie2 v.2.4.2 (Langmead and Salzberg 2012); 2. Pseudoalignment using

207 Kallisto v.0.46.0 (Bray et al. 2016) were used to assess differentially expressed genes across

208 tissues and developmental time points. Counts for HTSeq2 and Bowtie2 alignment files were

209 obtained using HTSeq-counts computed for the Xenopus tropicalis v.9 annotations. Kallisto

210 counts were also used as a comparison method. The subsequent steps are for the aligned

211 transcripts obtained from the HT-seq2 step. The differential gene expression between the two

212 tissue types (coccyx and hypochord), three developmental stages, and three biological replicates,

213 were analyzed using the DESeq2 (Love, Huber, and Anders 2014) package (v.3.12) from

214 Bioconductor. The dataset consisted of a total of 18 libraries (9 individuals, 3 replicates, 2 tissue

215 types, 3 stages), differentially expressed genes were looked for either between stages (e.g.,

216 prometamorphosis vs beginning of metamorphic climax) or between the two tissue types (e.g.,

217 coccyx $v s$ hypochord). A DESeq2 negative binomial generalized linear model was adapted,

218 which has been highlighted in previous studies (Love, Huber, and Anders 2014) as a robust 
219 method for identifying differentially expressed genes (DEGs). DESeq2 package was used in R to

220 normalize the reads, and the reads were subjected to variance stabilizing transformation using the

221 "vst" function. A principal component analysis (PCA) was carried out using the DESeq2

222 function "plotPCA" to observe the clustering of the 18 samples. Hypochord and coccyx show

223 considerable differences in cellular composition and differentiation (Senevirathne et al. 2020),

224 and the gene expression profiles directly reflect this (Fig. 1C). A False Discovery Rate (FDR)

225 value of $<0.05$ was used as the statistical significance threshold. DEG comparisons were

226 depicted in three ways: prometamorphosis $v s$ beginning of metamorphic climax; beginning of

227 metamorphic climax $v s$ end of metamorphosis; coccyx $v s$ hypochord. The results of the DEG

228 experiments were visualized in three main ways: 1 . heatmaps were generated from the lists

229 (Appendices C, D and Tables 3.1 and 3.2) of significant genes using the normalized values.

230 Differences in expression data were visualized using z-scores calculated for each gene (=each

231 row); 2. Volcano plots were drawn highlighting the up/down regulatory genes in the DEGs.

232 Here, log-transformed p-values (y-axis) were plotted against the log2 fold change (x-axis); 3.

233 Narrowed down gene symbols of the DEGs were used for GO enrichment analysis. The

234 reactome web-based analysis tool was used to determine the overrepresentation of Reactome

235 pathways where the up/down regulatory gene lists (Appendices C,D,E and F), genes within the

236 intersections of the Venn Diagrams (drawn using the package "VennDiagram") were given as

237 inputs.

\section{ATAC-seq analyses}


Adapter sequences were trimmed from the raw paired end 100-bp files using NGmerge (Gaspar 2018) and the trimmed sequences were aligned to the $X$. tropicalis reference genome v. 9.1

241 (Xenopus_tropicalis_v9.1.dna.toplevel.fa.gz) using Bowtie2. Duplicated reads were removed

242 from the subsequent analyses using Picard (http://broadinstitute.github.io/picard/). Peaks were

243 called using MACS2 (Zhang et al. 2008) (--nomodel --extsize 200 --shift -100 --nolambda) and

244 Genrich (-e chrM -r -j). Two peak callers were used to compare the peaks, where Genrich's “j”

245 command specifically signifies the ATAC-seq mode. Irreproducible discovery rate (IDR) $<0.01$

246 was used as the threshold to screen the replicate samples. Here, the IDR method compares

247 ranked peak lists to identify overlapping peaks. Finally, the peak files were directly uploaded to

248 Integrative Genomics Viewer (IGV) and were visualized along with their respective. bam and

249 bam index files.

251 HCR in-situ hybridization

252 Targeted urostyle tissues were fixed in 4\% PFA, dehydrated in a methanol series, and stored at -

$25320^{\circ} \mathrm{C}$ until future use. On the day of sectioning, tissues were rehydrated using an ethanol series, 254 rinsed in histosol, and subsequently, washed and mounted in paraffin. The microtome, brushes,

255 bench/tabletops were cleaned using RNAse away and 100\% ethanol and the tissue blocks were

256 sectioned to obtain $12 \mathrm{uM}$-thickness paraffin sections. Paraffin sections can be stored at room

257 temperature, indefinitely, until the day of staining.

258 For HCR in-situ hybridization (Yamaguchi et al. 2015) of paraffin sections (the protocol 259 followed https://www.molecularinstruments.com/protocols with slight modifications), the 
260 sections were initially dewaxed using histosol, re-hydrated in ethanol, and treated with a

261 Proteinase K/PBS solution to increase the tissues' permeability. Prehybridization step was

262 followed by the addition of the targeted probe $(1 \mu \mathrm{M}$ probe/100 $\mathrm{ul}$ of hybridization buffer $)$ and

263 leaving the slides in a $37^{\circ} \mathrm{C}$ incubator overnight. Next day, the slides were washed in the wash

264 buffer and subjected to an amplification buffer with hairpins overnight. On the third day, the

265 slides were washed using dilution a series of SSCT, mounted using Fluoromount G + DAPI, and

266 visualized using a Zeiss LSM 710 confocal microscope. The results were analyzed using Fiji

267 image analysis software.

\section{4 - RESULTS}

\section{Disparity in gene expression profiles of the Coccyx and Hypochord}

271 At the beginning of metamorphic climax (stage 60/61) both hypochordal and coccygeal cells

272 underwent chondrogenesis and osteogenesis (dissected cells at this stage included immature

273 chondrocytes, mature chondrocytes, osteocytes, mesenchymal cells, and extracellular matrix)

274 (Fig. 1A and 2). At the end of metamorphosis, coccygeal and hypochordal cells completed

275 ossification, and the majority of the cells consisted of osteocytes, osteoblasts, and mature

276 chondrocytes. The two tissue types fuse at the end of metamorphosis, coinciding with the

277 degeneration of the notochord. The total analysis consisted of 21458 genes, out of which 3286

278 genes exhibited considerable variation between the two tissue types across development (the

279 FDR $<0.05$ ); both tissue types and the three timepoints were used as factors in the DESeq2 
280 analysis where a binomial generalized linear model was implemented. Principal component

281 analysis (PCA) revealed that the coccygeal and hypochordal samples generate two separate

282 clusters (Fig. 3B), and a heatmap showed the two tissue types possess two different gene

283 expression profiles (Fig. 3C). 3298 genes were differentially expressed between the urostyle and

284 hypochord, whereas 1845,385 and 3434 genes were differentially expressed between the

285 prometamorphic $v s$ beginning of metamorphic climax, beginning of metamorphic climax $v s$ end

286 of metamorphosis, and prometamorphosis $v s$ end of metamorphosis, respectively. Among these

287 DEGs, 2828 genes were significantly upregulated and 470 were downregulated in the coccygeal

288 region compared to hypochord. During coccygeal development, several modifications happen

289 around the areas of interest. The coccyx develops dorsal to the notochord and around the spinal

290 cord, initially as two ossification centers, which later fuse together during metamorphosis.

291 Concomitantly, muscles and neurons around the coccyx remodel. Primary myotomes remodel

292 into secondary muscles and attach to the coccygeal bone. The spinal cord degenerates and axons

293 project outwards from the coccygeal spinal foramina (Senevirathne et al. 2020). These

294 phenotypic changes are reflected in the underlying gene regulatory networks. The majority of the

295 upregulated genes in the coccygeal tissue samples are involved in differentiation and

296 development of the nervous system (e.g., NEUROD6, PRDM12, COCH, APBA2)

297 (Uittenbogaard, Baxter, and Chiaramello 2010; Rahman et al. 2020), or are genes that are

298 expressed during skeletal muscle development (e.g., ACTN2) (Mills et al. 2001). Apart from

299 these, the rest of the upregulated genes within coccygeal tissues are directly involved in 
300 chondrocyte/osteocyte differentiation (e.g., RUNX2, COL9A1, SOX8) (Fig. 3) (Youlten et al.

301 2020; Qin et al. 2020).

Embryonic hypochordal cells are thought to have an endodermal (Cleaver and Krieg

303 1998; Cleaver, Seufert, and Krieg 2000; Lofberg and Collazo 1997; Senevirathne et al. 2020) or

304 a superficial mesodermal origin (Shook, Majer, and Keller 2004). Whether it is endoderm- or

305 superficial mesoderm-derived, a cell population that is completely different from the sclerotomal

306 cells (of the coccyx) forms the ossifying hypochord and contributes to the adult axial column.

307 Hence, this unusual ossification of the hypochord, seen only in anurans (ranging from the

308 myotome 10-14), is considered an apomorphic state, compared to the rest of the vertebrates.

309 Embryonic hypochordal cells undergo chondrification and ossification as soon as the tadpole

310 reaches its metamorphic climax. The transcriptomic assay between the two tissues revealed that

311 hypochordal tissues express high concentrations of TBX1, TBXT.1, TBXT.2, and HAND2 (Fig.

$3123 \mathrm{C}$ ). T-box genes are involved in early mesodermal patterning and their expression has not been

313 recorded in adult tissues before (explained in detail in a subsequent section; 3.4.3). Here, we

314 hypothesize three possible scenarios: if the hypochordal cells are of endodermal origin, the

315 increased TBXT/TBXT.2 could be initiating a cell-fate switch from endoderm-to-mesoderm (there

316 are some instances where T-box genes have been recorded to enable a cell-fate switch e.g.,

317 (Chapman et al. 2003)). To the best of our knowledge, there are no other studies looking into the

318 possibility of an endoderm-derived tissue undergoing ossification. Secondly, if the hypochordal

319 cells are superficial mesoderm derived, TBXT and TBXT.2 could be activating the downstream

320 targets involved in cellular matrix organization (seen by the up-regulated expression patterns of 
$321 M M P 1, M M P 8$; Fig. 3) and chondrification. Thirdly, another possibility is that the ossification of 322 the hypochord could resemble an epithelial-to-mesenchymal transition (EMT). During EMT, the 323 epithelial cells adapt a morphology similar to fibroblasts and acquire migratory properties (at the 324 same time the epithelial cells lose adhesion to the surrounding extracellular matrix) (Radisky 325 2005). Several studies hypothesize how Brachyury (TBXT/TBXT.2) plays a pivotal role in 326 EMT, where overexpression of Brachyury would induce mesenchymal properties, and reduce 327 epithelial properties, in the migrating epithelial cells (Behr et al. 2005; Fernando et al. 2010). 328 This phenomenon has led to abnormal ossifications in the vertebral column (i.e., vertebral 329 column chordomas, where some are observed between the notochord and vertebral column)

330 (Chen et al. 2020; Vujovic et al. 2006; Zhu, Kwan, and Mackem 2016). There are endothelial 331 cells lying between the embryonic hypochord and endoderm (where the dorsal aorta runs 332 between these two tissues) (Senevirathne et al. 2020). Hence, the increased expression of $333 T B X T / T B X T .2$ in hypochordal cells could potentially lead to increased mesenchymal properties 334 and eventually activate chondrifying and ossifying genes.

T-box genes have already been identified as being pivotal components in the 336 differentiation of the posterior axial column (Chen et al. 2020; Cunliffe and Smith 1994, 1992;

337 Gentsch et al. 2018; Ghebranious et al. 2008; Hayata et al. 1999; Hotta et al. 2000; Messenger et 338 al. 2005; Schulte-Merker and Smith 1995; Vujovic et al. 2006; Wan et al. 2016), and seem to be 339 playing a role in hypochordal ossification as well. However, all the three scenarios explained 340 above, would require the activation of T-box genes at the onset of metamorphosis because of 341 extrinsic/intrinsic signals, which could be either hormonal or environmental. 
The pelvic region undergoes dramatic changes during metamorphosis, and this period is

343 thought to represent the developmental stage that is most susceptible to predation. The

344 underlying stress of the remodeling tissues and hormonal responses can also be seen by the

345 increased expression of $C R C H .1$ (corticosol steroid stress hormones), having a normal hormonal

346 response to stress. Other than these genes, the hypochord also expresses significant

347 concentrations of $V E G F$ and $H A N D 2$. These two genes are involved in vascular development and

348 can also be seen expressed in embryonic hypochord where $V E G F$ plays a role in the formation of

349 the hypochord (e.g., (Cleaver and Krieg 1998; Cleaver, Seufert, and Krieg 2000; Cleaver et al.

350 1997)). Our previous work (Senevirathne et al. 2020) showed how the ossifying hypochord may

351 also play a role in modifying the dorsal aorta by occluding it at the posterior-most end of the

352 hypochord and remodeling it to form two branches, which enter the fore- and hind limbs

353 respectively.

\section{Transcriptomic differences across different time points during urostyle development}

356 The coccygeal and hypochordal tissues chondrify and ossify during development. At the end of

357 metamorphosis, coinciding with the degenerating notochord, they fuse together to form the

358 urostyle. We next delved into identifying genes that switch on/off during metamorphosis and

359 highlight DEGs that are expressed at each time point: before metamorphosis, beginning of

360 metamorphic climax, and end of metamorphosis.

361 There are numerous studies of metamorphic transcriptomes (e.g., (Brown and Cai 2007;

362 Callery and Elinson 2000; Zhao et al. 2016; Wang et al. 2019; Yaoita and Brown 1990; 
363 Kanamori and Brown 1996; Brown et al. 1995)), but none on the urostyle. We first looked into

364 urostyle-responsive transcriptomes by comparing genes that are differentially expressed in the

365 coccyx and hypochord at different time points: 1. Before metamorphosis vs beginning of

366 metamorphosis (electronic supplementary material, figures S1B, S2 and S3) and

367 before/beginning of metamorphosis vs end of metamorphosis (electronic supplementary material,

368 figure S1A). This analysis identified 5664 number of DEGs that fell within the thresholds of

369 FDR $<0.01$ (adjusted p-values $<0.05$ and log fold change of 1.5) and showed unique expression

370 patterns that were significant at each time point.

371 Several unique sets of genes were up- and down-regulated across the three developmental

372 time points (Fig. S1). Through this step, we identified 4 unique clusters when the transcriptomes

373 were compared between the three developmental time points (before and beginning of

374 metamorphosis $v s$ end of metamorphosis (electronic supplementary material, figure S1). Cluster

375 A has 47 genes that were highly downregulated at the end of metamorphosis ("switched off")

376 compared to the other two time points. This cluster includes genes involved in muscle

377 contraction and M-band stabilization in fast skeletal muscles (e.g., TRDN and MYOM2I;

378 (Giacomazzi et al. 2017; Auxerre-Plantie et al. 2020)), skeletal development (e.g., SOX9 (Hattori

379 et al. 2010)), response to inflammation (PTX3; (Magrini, Mantovani, and Garlanda 2016)),

380 filament organizing genes (e.g., KRT18.I and VIM.2; (Velez-delValle et al. 2016; Gan et al.

381 2016)), extracellular matrix organizing and connective tissue-strengthening (e.g., COL9A1,

382 COL8A1, CHAD; (Brachvogel et al. 2013; Hessle et al. 2014)), and stress regulation (CRCH.1;

383 (Reul and Holsboer 2002)). The other two gene clusters, B and C (electronic supplementary 
material, figure S1A), comprise genes that are both down- and up-regulated at the end of metamorphosis. Cluster $\mathrm{C}$ also has 15 genes that are downregulated at the end of metamorphosis, which include collagen markers (e.g., COL9A3), and skeletal muscle function genes (e.g., MYL1 and ACTN3; (Schiaffino et al. 2015; Pickering and Kiely 2017)). Genes that are up-regulated (10 genes) are within Cluster B and are involved in mitosis (CCNB1; (Strauss et al. 2018)), development of neurons (POU3F1; (Zhu et al. 2014)) and maintenance of myelin sheath (PLP1;

390 (Gould et al. 2008)). When before metamorphosis was compared with beginning/end of

391 metamorphosis, clustering of the 100 top-most significant genes revealed metamorphic genes

392 that were switched off before metamorphosis but were switched on during metamorphosis.

393 Heatmap clustering revealed five main clusters (electronic supplementary material, figure S1B).

394 Cluster A included 28 genes that were downregulated (switched off) before metamorphosis in 395 both coccyx and hypochord, but as soon as metamorphosis was initiated, these genes were 396 upregulated; they are involved in functions like collagen synthesis (SERPINH1; (Widmer et al.

397 2012)), cell cycle (CDK6; (Tigan et al. 2016)), and thyroid hormone inactivation (DIO3; (Bianco 398 and da Conceicao 2018)). Cluster B and C includes genes that are switched on prior to 399 metamorphosis and are switched off at the onset of metamorphosis: HES8, FOXP2, EGR1, $400 H O X D 11$, and $P V A L B$ are representative examples. Cluster D is enrichened with genes that are 401 involved in blood sugar control (e.g., THRAP3, IGF2BP3; (Choi et al. 2014; Dong et al. 2017)), 402 which are down-regulated before metamorphosis but are up-regulated at the onset of 403 metamorphosis. This part of the transcriptomic analysis identified DEGs that are specific to the 404 three significant time points (before metamorphosis $v s$ onset of metamorphosis $v s$ end of 
metamorphic climax). We next explored the GO function of these significant genes during development. The DEGs and the corresponding P-values from the differential expression

407 analyses were imported into an online database of reactome pathways ("Reactome pathway

408 browser") to compare the functional aspect of these genes (electronic supplementary material,

409 figure S2). DEGs up regulated before metamorphosis were enriched for GO terms like "DNA

410 replication and pre-initiation", "synthesis of DNA", "Polymerase switching", "G1/S transition"

411 (Fig 3.5.B). Whereas the DEGs up regulated during metamorphosis include genes that function

412 in "Collagen formation", "Cross linking of collagen fibrils", " $R U N X 2$ regulated bone

413 development", and "Osteocyte differentiation" (Fig 3.5.C and D).

414 Morphological analyses highlighted that both urostyle and hypochord undergo

415 endochondral ossification during development (Senevirathne et al. 2020), and similar ossification

416 patterns were reflected in the gene expression profiles as well. Though there were major

417 differences in some transcriptomes (e.g., presence of T-box genes, CRCH.1, MMPs in

418 hypochordal tissues at the onset of metamorphosis vs absent in the coccyx), there were

419 similarities in genes that were involved in endochondral ossification: we show that genes that are

420 involved in cartilage and bone formation, extracellular matrix organization, and thyroid hormone

421 responsive elements are present in both tissues (electronic supplementary material, figure S2),

422 but differ temporally (coccyx starts ossifying after 1.5 months, whereas the hypochord initiates

423 its ossification only at the onset of metamorphosis). 
426 The ossifying hypochord in anurans is considered an unique feature. As there is no data on the 427 genes that are expressed during hypochordal ossification, we used the DEGs identified by the 428 coccyx $v$ s hypochord comparisons (section 3.4.1) to scrutinize this. This analysis identified 470 429 genes that were uniquely up-regulated only within the hypochordal tissues (they fell within the 430 significant threshold of adjusted $\mathrm{p}$-value $<0.05$ and $\mathrm{FDR}<0.01$ ) (Appendix B). Compared to the 431 coccyx, we identified DEGs that were only present in the hypochord (Table 3.2). Out of these, 432 here, we will be focusing on the highly expressed T-box (TBXT.1, TBXT.2, TBX1) genes that are 433 only seen in the hypochordal tissues in this section.

T-box genes have been implicated in early mesodermal patterning and, especially,

435 Brachyury/Xbra is essential in early mesodermal formation (Cunliffe and Smith 1994, 1992;

436 Hayata et al. 1999; Messenger et al. 2005; Smith et al. 1991), and Brachyury homologues across

437 vertebrates induce the mesoderm (Schulte-Merker and Smith 1995; Yasuoka, Shinzato, and 438 Satoh 2016). Xenopus has two paralogues of the gene Brachyury: TBXT.1 (also known at Xbra or 439 T) and TBXT.2 (also known as Xbra3 or T2). When Brachyury is knocked out, it causes loss of 440 posterior mesoderm and failure to differentiate the notochord (Gentsch et al. 2018; Paraiso et al. 441 2019). Brachyury is also involved in controlling cell fate decisions while acting synergistically 442 with the other transcription factors (like Bix4) and genes (WNT11) in the posterior mesoderm 443 (Showell, Binder, and Conlon 2004). However, the expression of TBXT.1 and TBXT.2 in late 444 developing tadpole structures has not been reported so far.

445 As described below, the temporal and spatial expression patterns of TBXT.1 and TBXT.2, 446 make them good candidate genes for regulating ossification only in hypochordal tissues. To 
447 study the potential role of TBXT.1 and TBXT.2 in hypochordal ossification further, we performed

448 HCR in-situ hybridization to examine the temporal and spatial expression patterns. TBXT.1

449 expression is exclusively concentrated along the ossifying hypochord at the onset of

450 metamorphosis but is not evident in prometamorphic nor at the end of metamorphic climatic

451 tadpoles (Fig. 4).

452 An ossifying hypochord is only normally present in anurans, however, interestingly, 453 hypochord ossification between the caudal part of the vertebral column and notochord also

454 appears as a congenital vertebral anomality seen prenatally in humans, caused by a mutation in 455 the T (TBXT) gene (Postma et al. 2014; Ghebranious et al. 2008). In humans with this

456 abnormality, increased expression or duplications of the $T B X T$ gene result in production of 457 excess Brachyury (Zhu, Kwan, and Mackem 2016; Chen et al. 2020). It has been hypothesized 458 that this excess Brachyury causes residual cells ventral to the notochord to grow and ossify in 459 humans and sometimes results in sacral agenesis in newly born babies (commonly to referred to 460 as the "frog-like" syndrome). The observation of high levels of $T B X T / T B X T 2$ in ossifying 461 hypochordal cells (which is ossified ventral to the notochord) and presence of two duplicated 462 copies of the $T B X T$ ( $T$ and $T 2 / T B X T$ and $T B X T .2$ ) in anurans compared to normal humans and 463 other vertebrates is thus tantalizing and needs further scrutiny. Previous studies have shown that 464 Brachyury acts as a switch in posterior mesoderm specification during embryogenesis and is 465 restricted to the anteroposterior axis (Cunliffe and Smith 1994, 1992). Here, during hypochordal 466 ossification, the onset of metamorphosis could be triggering ectopic expression of $T B X T / T B X T .2$ 467 in hypochordal cells, which could potentially express posterior mesodermal genes and 
468 subsequently activate down-stream targets of $T B X T / T B X T 2$, which in turn initiates

469 chondrification and ossification.

\section{Transcriptomic comparisons between coccyx + hypochord and other ossifying elements}

$472 \quad$ Vertebrate ossification happens by two major processes: endochondral (cartilaginous

473 precursors used as a template) and intramembranous (direct ossification of the condensed

474 mesenchymal cells) (Breeland, Sinkler, and Menezes 2021). Even though coccyx and hypochord

475 are derived from two different cell populations, they both undergo endochondral ossification

476 (Senevirathne et al. 2020). During this process, mesenchymal cells condense (commit to form

477 osteoprogenitors) and aggregate to form cartilaginous precursors during early development.

478 Cartilaginous precursors expand and cells proliferate, next the extracellular matrix is

479 synthesized, and finally, mineralization of the matrix occurs. These steps are similar to other

480 bones in vertebrates, which undergo endochondral ossification as well (Mackie et al. 2008).

481 However, to see if the transcriptomic profile during this process is conserved in the two bones

482 that form the urostyle, we compared the spatial and temporal transcriptomic maps of the

483 osteocytes (from published datasets of different skeletal tissues of different ages) with my

484 current dataset.

Youlten et al. (Youlten et al. 2021) identified three clusters of gene ontology (GO)

486 functions during osteocyte development: 1. "An early expression cluster" (expressed in

487 osteoprogenitors/osteoblast-like cells); 2. "An early activation cluster" (expressed in early

488 osteocytes); 3. "A maturation cluster" (expressed in mature osteocytes). We compared the 
expression of the genes belonging to these GO functions with the coccygeal and hypochordal transcriptomics to see if the molecular underpinning of ossification is similar in the genes

491 responsible for the formation of the urostyle as well.

492 Early expression cluster. - This included GO term functions "Extracellular matrix organization",

493 “Angiogenesis", "Cartilage development", and "Connective tissue development" (electronic

494 supplementary material, figure S4). Out of the genes that are differentially expressed, there are

495 some that are inactive before metamorphosis in the hypochord (e.g., COL22A1, COL16A1,

$496 C O L 6 A 3, R U N X 1, I H H)$, but are highly expressed once the metamorphosis is initiated. High

497 expression of these genes in the coccygeal cells even before the onset of metamorphosis

498 corroborates our morphological studies, where we revealed that the post caudal vertebrae of the

499 coccyx initiated mesenchymal cell aggregation early in development (1.5 months after

500 embryogenesis) vs 2 months in hypochord. Apart from the differences in the temporal expression

501 of genes within the "Early expression cluster", a few genes involved in cartilage development are

502 not present in the hypochord compared to the coccyx (e.g, FOXL1, RUNX3, FOXD3, PMM2,

503 EDN1).

504 Early activation cluster. - This cluster includes the GO terms "Axon guidance", "Axon

505 development", "Axogenesis", "Regulation of axogenesis", and "Neuron projection guidance"

506 (Fig. 5). While the coccyx DEGs act in a similar way to the rest of the long bones in vertebrates

507 within this cluster, hypochord shows a different pattern. Most of the genes (e.g., NTRN,

508 SLITRK3, POUF42, DCC) that are discussed as essential regulators in guiding the axons in long 509 bones are not expressed within the hypochord (Fig. 5). 
510 Maturation cluster. - The GO term functions "Bone development", "Skeletal system

511 development", "Regulation of ossification”, “Ossification”, “Osteoblast differentiation” are

512 included in this cluster (supplementary material, figure S5). Maturation period in the hypochord

513 happens once the metamorphosis is initiated and when the tadpole reaches the end of its

514 metamorphic climax (supplementary material, figure S5). Within the hypochord, genes involved

515 in ossification (e.g., GPC3, TMEM19, IFITM5, COL11A1, PHOSPHO1, SOX8) and osteoblast

516 differentiation (e.g., GLI1, FBN2, SATB2) are highly expressed in tadpoles at the end of the

517 metamorphic climatic and are inactive at prometamorphic stages. Comparatively, in the coccyx,

518 since the ossification happens prior to the metamorphic climax, the majority of the genes are

519 highly expressed even at the beginning of metamorphosis. A few genes (e.g., TBX15, $B A R X 2$,

$520 S H H, A X I N 2)$ are not expressed in hypochord nor in the coccyx, compared to the other ossifying

521 long bones in vertebrates.

522 This transcriptomic comparison led to three main findings: (1). Between the two tissue types, the

523 coccyx's DEGs share similarities with the other bones' transcriptomics in vertebrates. (2).

524 Hypochord undergoes its early activation period before metamorphosis, and a maturation period

525 once metamorphosis is initiated. (3) Hypochordal DEGs lack an early activation period, which

526 includes most of the axon developing genes.

529 During anuran metamorphosis, the larval body form undergoes dramatic remodeling within 6-8 
531 be extrapolated that gene regulation changes over this same time period. To study the underlying

532 changes in chromatin accessibility, we used an ATAC-seq approach using the same

533 developmental stages and the same number of replicates as the RNA-seq work. The number of

534 peaks varied between the three stages that we used: before metamorphosis (4563 peaks),

535 beginning of metamorphosis (6805 peaks), and end of metamorphosis (6805 peaks). More than

$53650 \%$ of peaks were distributed in distal intergenic regions. The rest of the peaks were distributed

537 along intronic, exons, and promoter regions. When comparing the three time points, the most

538 significant change of peak distribution observed was the percentage of peaks that fell on the exon

539 regions (other than the $1^{\text {st }}$ exon): before metamorphosis the percentage was lower $(<1 \%)$ when

540 compared with the number of peaks that were seen at the beginning and at the end of

541 metamorphosis (7-10\%) (Fig. 6B).

Next, we compared the ATAC-seq data with the RNA-seq data and observed that

543 majority of the peaks are located close to the up-regulated genes in the hypochord and coccyx

544 that were identified from the transcriptomic data. The genes $T B X T$ and $T B X T .2$, which are up

545 regulated in the hypochord, have peaks located within the intronic regions before and at the

546 beginning of metamorphosis, and the peak is lost at the end of metamorphosis (Fig. 6D). Other

547 genes expressed in hypochordal tissues like $M M P 1$ and COL22A1 have peaks downstream of the

548 genes and are seen only once the metamorphosis is initiated. Genes that were upregulated in the

549 coccyx, e.g., $H O X D 11, P V A L B, D I O 3$, and ACTA2 have ATAC-seq peaks closer to each gene

550 and were present throughout development (Fig. 6C-E). This could be because the coccygeal

551 ossification occurs early in development (after 1.5 months) compared to the hypochord. These 
552 results highlight urostyle-responsive regulatory regions during development and need further

553 scrutinization using functional assays.

\section{DISCUSSION}

556 The anuran urostyle, composed of a coccyx and a hypochord, reflects how novel structures

557 facilitate evolution of new body plans. Our previous work presented a morphological analysis of

558 the ontogeny of the anuran urostyle using immunohistochemistry, histology, bone and cartilage

559 staining, and microCT scanning. Through this, we identified cells of interest and the

560 developmental stages to target for this follow up study. To elucidate how this structural novelty

561 arose and its genetic underpinnings, we used a spatial transcriptomic (RNA-seq) and an ATAC-

562 seq approach.

\section{T-box genes and the hypochord}

565 The coccyx and hypochord have two sets of differentially expressed genes. Hypochordal genes

566 are active at the onset of metamorphosis, whereas the coccygeal DEGs are highly expressed even

567 before metamorphosis. This analysis revealed a large set of genes (Tables 3.1 and 3.2 and

568 Appendices C, D) that are uniquely up regulated in the hypochord and have not been reported

569 before. One of the most significant groups of genes that is upregulated in the hypochord are the

570 T-box genes (TBXT and TBXT.2). T-box genes have a 180-bp DNA binding domain that is

571 highly conserved. Orthologues of the gene Brachyury, one of the highly expressed T-box genes 
572 in the hypochord, are present in all multicellular organisms (Chen et al. 2020). Brachyury is

573 important in posterior mesoderm development (initially expressed in the developing mesoderm

574 but later restricted to the tail bud and notochord) (Hotta et al. 2000). While early mesoderm

575 differentiation patterning depends highly on $T B X T / T B X T .2$, a role for these genes in later

576 developmental stages has not been previously reported or discussed. During metamorphosis, the

577 tadpole body undergoes dramatic remodeling, including tail loss and development of new

578 structures like the urostyle. The hypochord, thought to be of an endodermal or superficial

579 mesoderm origin, undergoes ossification at the beginning of metamorphosis only in anurans. We

580 hypothesize that presence of high levels of $T B X T / T B X T .2$ causes the hypochordal cells to

581 undergo ossification at the onset of metamorphosis. Such unusual ossification appears to also

582 occur in response to a congenital vertebral column malformation (VCM) in humans that happens

583 because of a Brachyury gene mutation in the intron 7 (Ghebranious et al. 2008) and in the highly

584 conserved T-box sequence (Postma et al. 2014); these VCMs eventually lead to sacral agenesis

585 ("frog-like") syndrome in babies. Apart from these mutations, TBXT/TBXT.2 genes also induce

586 EMT in humans when over expressed in carcinoma cells (Henderson et al. 2005), and it has also

587 been recorded that duplications of the Brachyury gene cause vertebral column chordomas

588 (Vujovic et al. 2006; Henderson et al. 2005). Frogs have two paralogues of Brachyury genes,

589 perhaps explaining the overexpression of $T B X T / T B X T .2$ at the onset of metamorphosis, which

590 could in turn allow the T genes to activate downstream targets that lead to chondrification and

591 ossification. When Brachyury genes are highly expressed in human chordoma cells, matrix

592 metalloproteinases (e.g., $M M P 12, M M P 13, M M P 24)$ (Wan et al. 2016) are also upregulated at 
593 the same time (which is also seen in hypochordal cells). The extent to which the human and frog

594 conditions are similar awaits functional tests.

\section{Coccyx and hypochord vs other vertebrate skeletal elements}

597 Coccyx and hypochord undergo endochondral ossification and show an array of genes that are

598 similar to the genes expressed in other long bones that undergo endochondral ossification in

599 vertebrates (e.g., mesenchymal-to-chondrocytes involved genes like $B M P \mathrm{~s}, S O X 9$; chondrocytes-

600 to-osteoblasts/osteocytes was seen in highly expressed genes like $R U N X 2$, Osterix, $I H H$ ). Apart

601 from these similarities, when comparing the already published osteocyte transcriptomics

602 (Youlten et al. 2021), hypochord shows some considerable differences among the rest of the

603 bones in vertebrates. Hypochordal cells express osteoprogenitor-specific genes before the

604 metamorphic climax, and metamorphosis acts as a switch that activates osteogenesis ( $v s$ in

605 coccyx osteogenesis is initiated prior to metamorphosis). Other than the temporal differences

606 observed regarding ossification, the DEGs of the hypochord reveal that hypochordal cells lack

607 the "early activation phase," which includes regulators needed in "Axogenesis" and "Axon

608 development" in ossifying bones (Fig. 5). Vertebrate bones are innervated by sensory and

609 sympathetic nerves during skeleton development (Tomlinson et al. 2020), where the periosteum

610 and bone marrow have the highest density of nerves whereas the mineralized matrix has very

611 few (Mach et al. 2002; Castaneda-Corral et al. 2011; Tomlinson et al. 2020). During

612 development, bone innervation and endochondral ossification happen simultaneously

613 (Tomlinson et al. 2020), and it is hypothesized that axon guidance regulates formation of the 
614 neuronal network, which is subsequently required for the osteocyte network formation (Youlten

615 et al. 2021). It is surprising that the ossifying hypochord lacks the genes needed for axon

616 development (Fig. 5), and our results raises the possibility that the hypochordal development

617 maybe disconnected from the neuronal signals. Future work is needed scrutinizing the

618 innervation patterns within the hypochord during its development to better understand this.

619 Our integrative approach, using morphological and molecular data sets (genes and gene 620 regulation) on the development of the urostyle, scrutinizes the evolution of a novelty. This has

621 been evolutionary favored for more than 200 million years and is seen in all extant anurans

622 during their development. We propose that the underlying changes in the genetic network gave

623 rise to the anuran urostyle, and it is an evolutionary novelty that has enabled successful

624 inhabitation of several ecological niches. Future work targeting the candidate genes responsible

625 for the development of the urostyle, together with functional assays, will shed light on the

626 evolution of this structural enigma.

\section{ACKNOWLEDGMENTS}

628 We would like to thank Marko Horb, Nikko-Ideen Shaidaini, and Marcin Wlizla (National

629 Xenopus Resource [NXR], Marine Biological Laboratory) for husbandry and providing $X$.

630 tropicalis tadpoles; James Hanken, Victoria Prince and Shubin Lab members for their comments

631 and helpful discussions on this work. This work was supported by University of Chicago

632 Biological Sciences and the Brinson Foundation (to N.H.S.) and by O’Brien and Hasten

633 Fellowship to G.S. 


\section{AUTHOR CONTRIBUTIONS}

636 G.S. and N.H.S conceptualized the project and designed research. G.S. Performed research and

637 analyzed data. G.S. wrote the paper with inputs from N.H.S. 


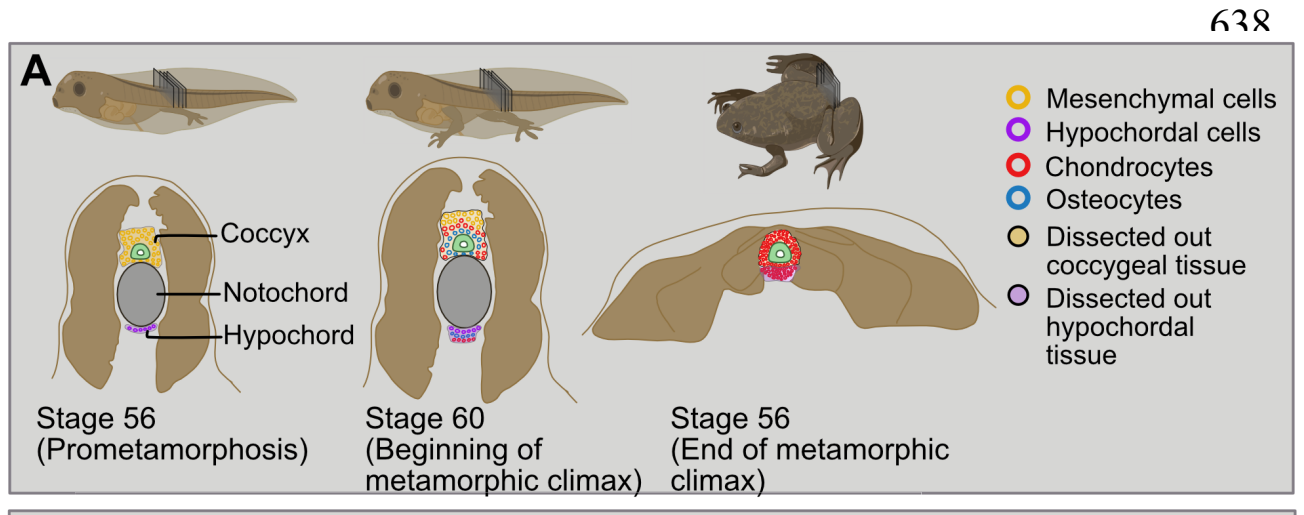

B

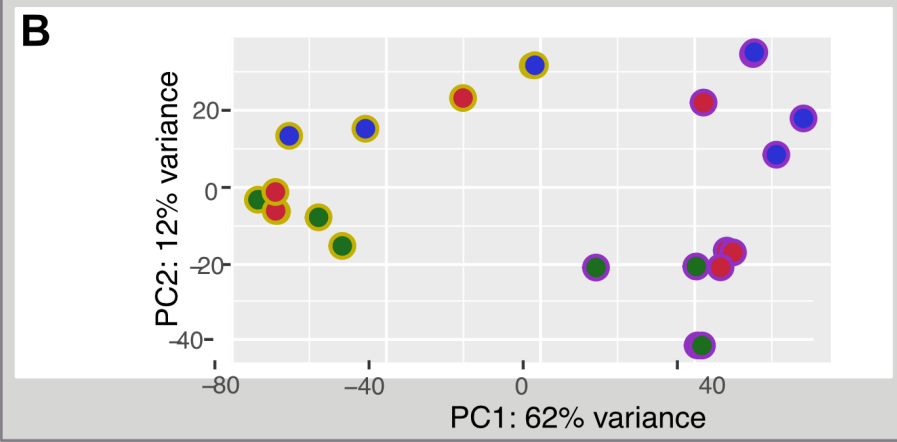

C
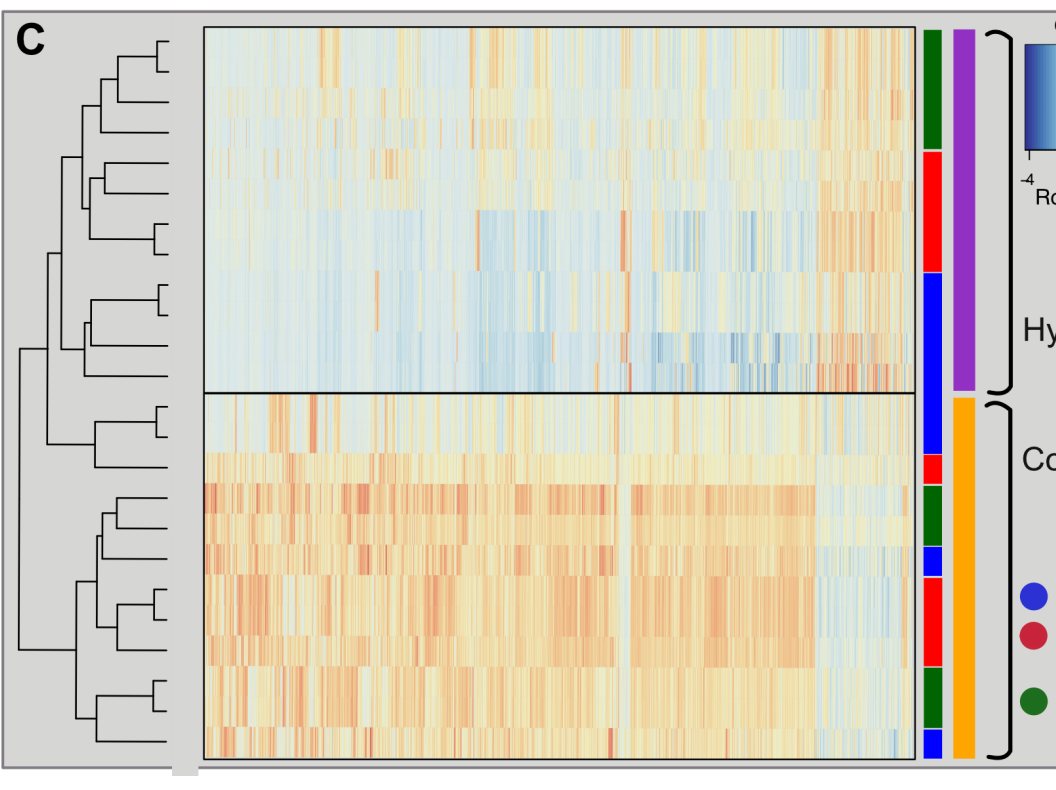

Color Key

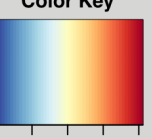

Row Z Z $^{0}{ }^{2}{ }^{4}$

Prometamorphosis

Beginning of

metmorphic climax

End of metamorphic

climax

o8 1

Figure 1: Changes in transcriptomics during anuran urostyle development. A. The experimental setup and the developmental stages used for Laser-capture microdissections. Ten sections of cryosections (16 $\mathrm{mM}$ each) were taken from three developmental stages (stage 56: prometamorphosis; stage 61: beginning of the metamorphic climax; stage 65: end of metamorphosis) and the coccygeal and hypochordal tissues were dissected out. B. Principal component analysis for the urostyle tissues (coccyx and hypochord) used for the transcriptomic assay $(\mathrm{N}=4$ biological replicates per developmental stage). B. Principal component analysis of the lognormalized count data for all 24 samples. Each dot represents a tissue sample. C. Heatmap, highlighting the differentially expressed genes, compared between three developmental stages and two tissue types. 683 The heatmap highlights that the two tissue types possess two distinct sets of genes. 
bioRxiv preprint doi: https://doi.org/10.1101/2021.10.04.462674; this version posted October 5, 2021. The copyright holder for this preprint (which was not certified by peer review) is the author/funder, who has granted bioRxiv a license to display the preprint in perpetuity. It is made

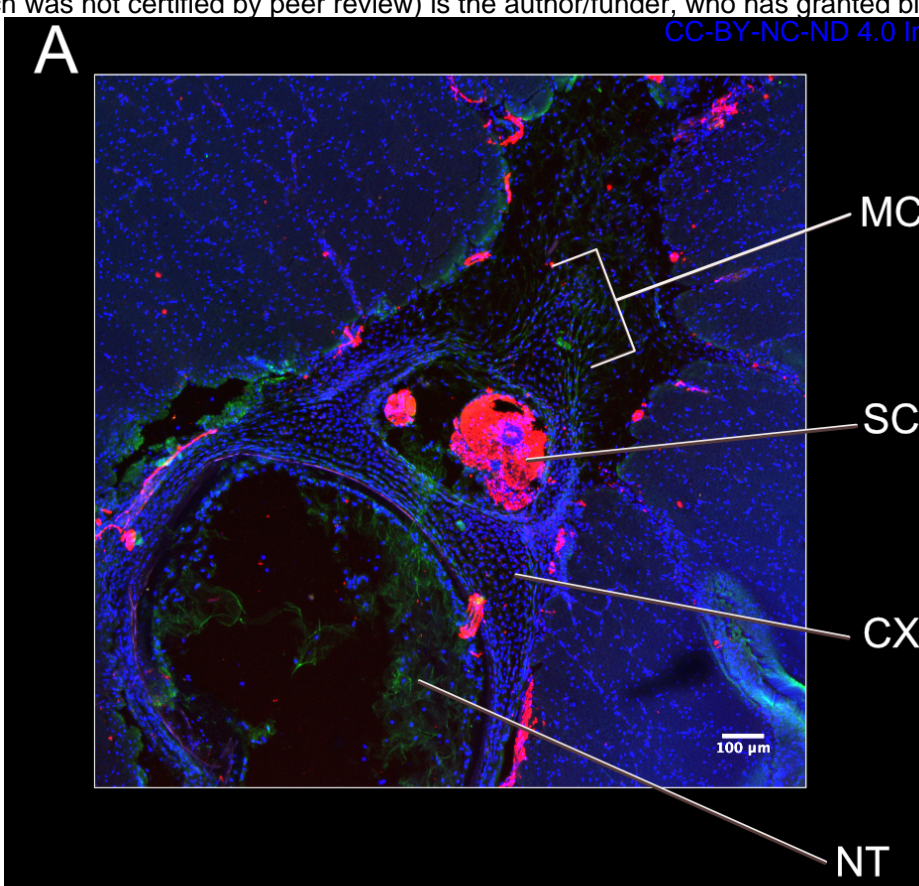

B

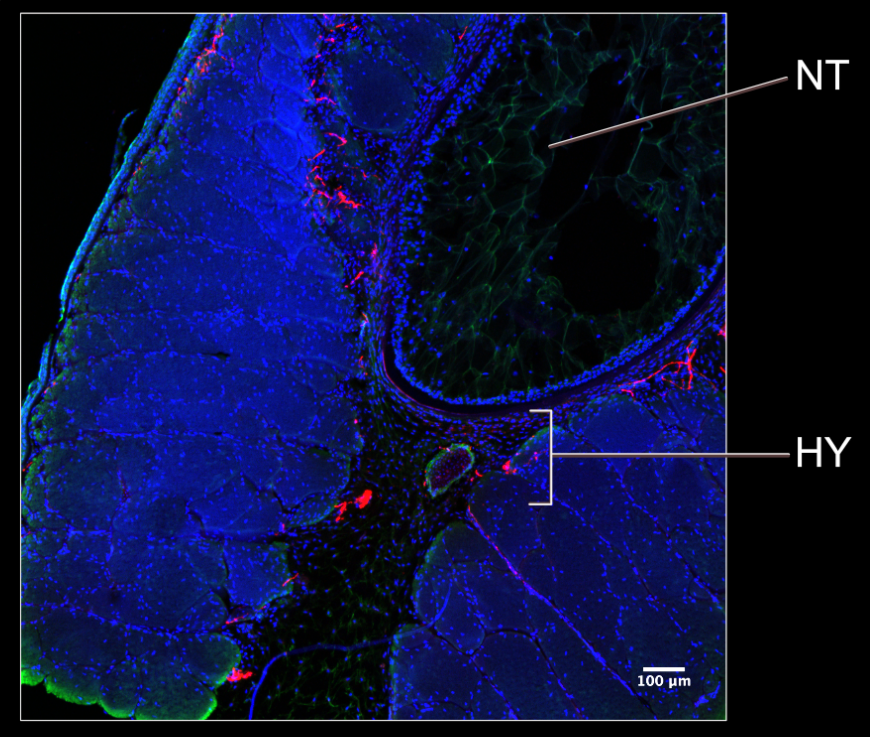

686 Figure 2: Comparison of the hypochordal and coccygeal sections before metamorphosis (stage 57). A. A transverse section across the hypochord, highlighting the embryonic hypochordal cells ventral to the notochord and notochordal sheath. Nuclei stained in blue, using DAPI and neurons stained in red using acetylated tubulin. 
bioRxiv preprint doi: https://doi.org/10.1101/2021.10.04.462674; this version posted October 5, 2021. The copyright holder for this preprint (which was not certified by peer review) is the author/funder, who has granted bioRxiv a license to display the preprint in perpetuity. It is made

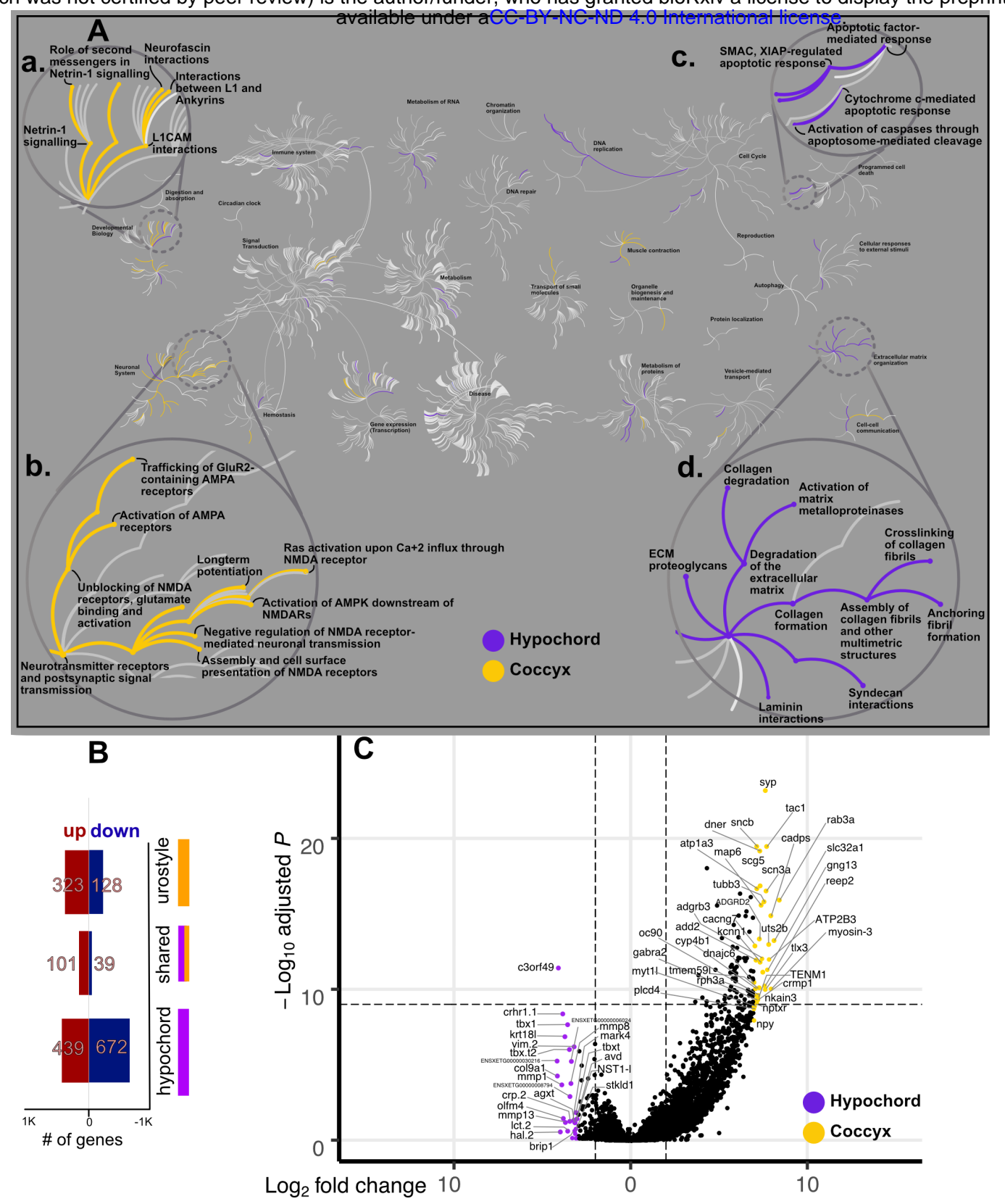

Figure 3: Comparative transcriptomic analysis of the two tissue types: coccyx and hypochord. A. A Reactome pathway analysis for up/down regulatory genes in coccyx vs hypochord; the central circles represent a top-level pathway, and the circles away from the center represents lower levels in each respective pathway. Zoomed-in sections of top-level pathways of Developmental Biology (Aa), Neuronal system (Ab), Programmed cell death (Ac), and Extracellular matrix organization (Ad) are shown. Overrepresented pathways $(\mathrm{P}<0.05)$ are colored in yellow (coccyx) and purple (hypochord). Pathways that are not significant are shown in light gray lines. B. Most hypochordal genes are involved in organizing the extracellular matrix, whereas the majority of coccygeal genes are involved in neuronal remodeling and modifications. B. The total number of urostyle-responsive genes (FDR $<0.01)$ between hypochord and coccyx. C. Volcano plot showing differentially expressed genes across hypochord and coccyx during development $(\mathrm{P}<0.05$, FDR $<0.01$ ). 
bioRxiv preprint doi: https://doi.org/10.1101/2021.10.04.462674; this version posted October 5, 2021. The copyright holder for this preprint (which was not certified by peer review) is the author/funder, who has granted bioRxiv a license to display the preprint in perpetuity. It is made available under aCC-BY-NC-ND 4.0 International license.

(C)
(C')

\section{HY}

$x=$
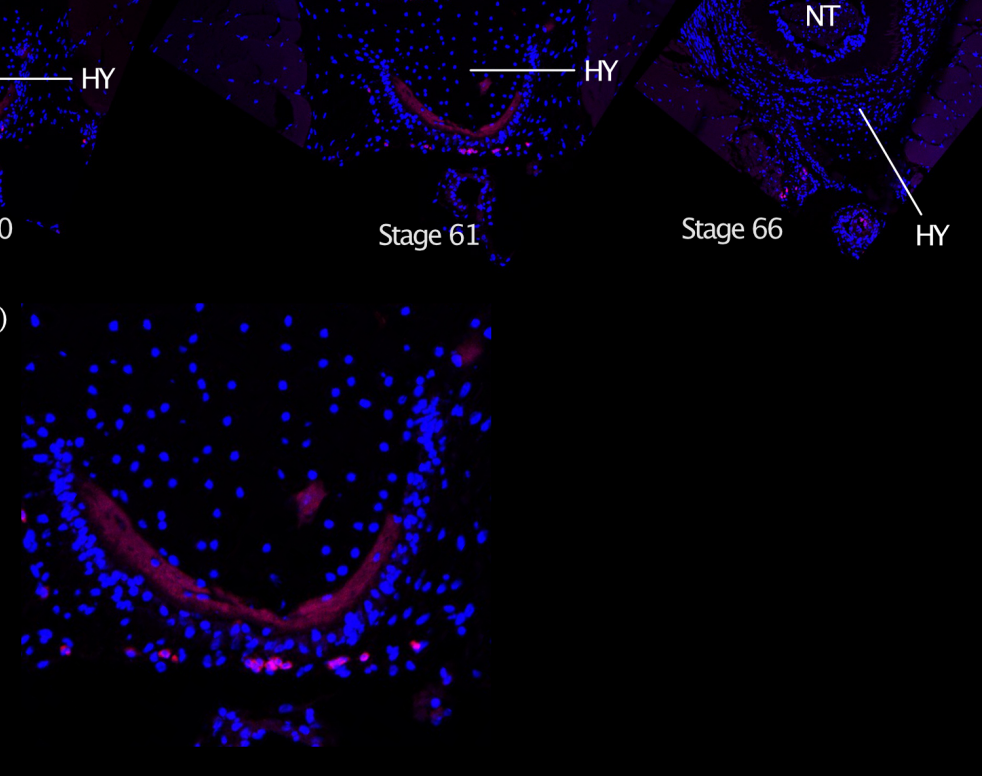

Figure 4. TBXT HCR in-situ hybridization on transverse sections of the urostyle. The periphery of the developing hypochord shows expression of TBXT (pink color), which is initiated once the hypochord starts to form and depletes when the hypochord fuses with the coccyx. Nuclei are stained using DAPI (blue). Abbreviations: CX, coccyx; HY, Hypochord; NT, notochord. 
Figure 5: Heatmaps showing differentially expressed genes involved in GO functions belonging to the "Early activation cluster" of osteocyte differentiation. Significant genes of the osteocyte transcriptome are divided into three clusters (Youlten et al. 2021). This cluster includes the GO functions Axon guidance, Axon development, Axogenesis, Regulation of axogenesis, and Neuron projection guidance. Genes of interest that are differentially 

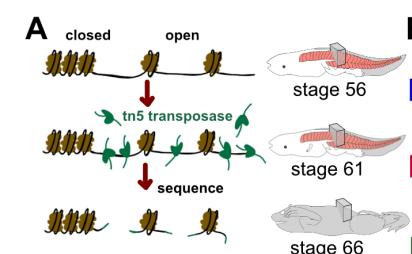

\section{C}

shared between hypochord and coccyx

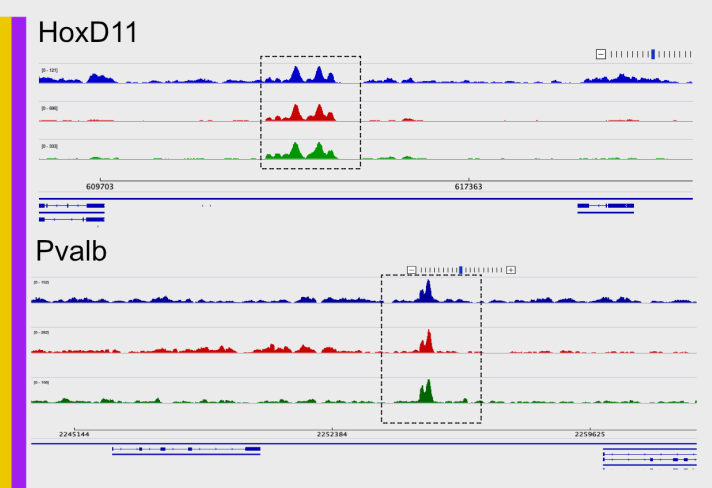

dio3

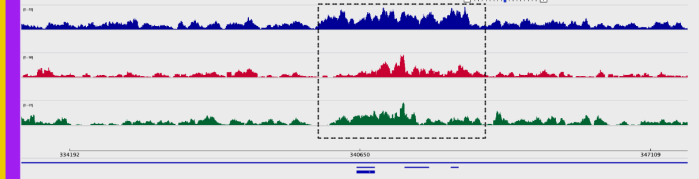

acta2

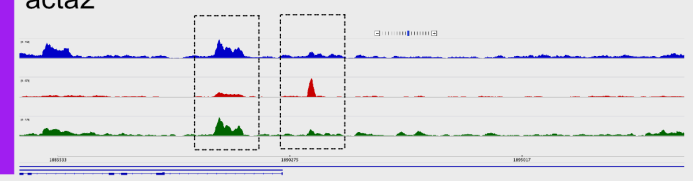

before metamorphosis

beginning of metamorphosis

end of metamorphosis

hypochord

coccyx

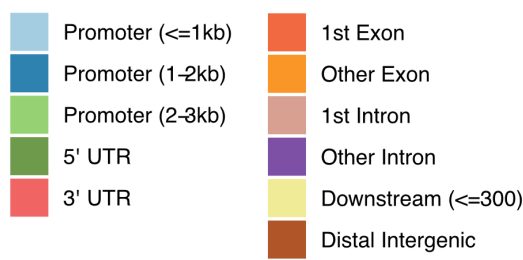

hypochord-specific

D

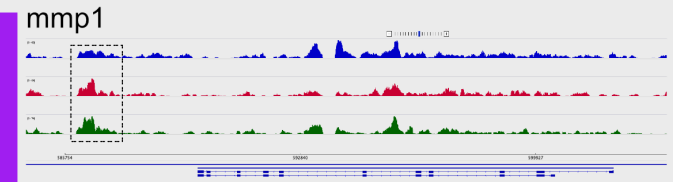

tbxt2

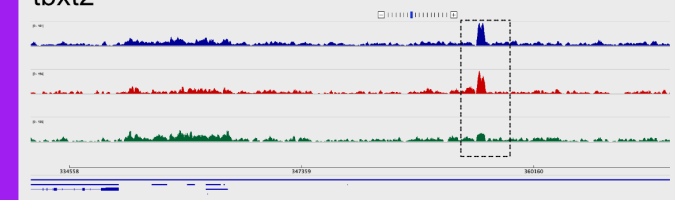

col22a1

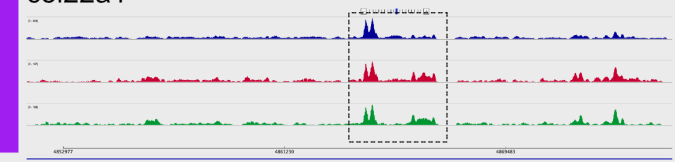

E coccyx-specific

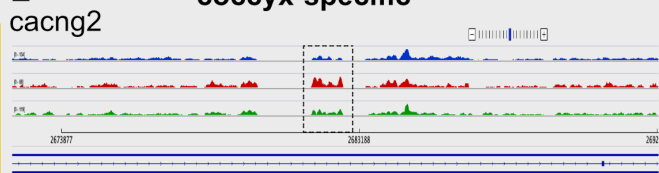

$\mathrm{COCH}$

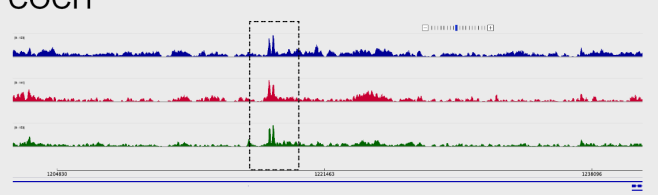

tmem159

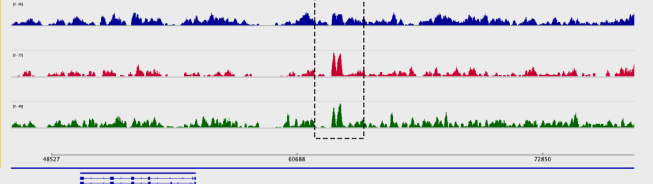

Figure 6: Urostyle-responsive regulatory regions. A. Schematic diagram showing the workflow for chromatin profiling experiment. B. Proportions of developing urostyle ATAC-seq peaks annotated to different genomic regions across development; majority of the peaks fall within the distal intergenic region and beginning (stage 61) and end of metamorphic climatic (stage 65) peaks differ from the prometamorphic (stage 56) ATAC-seq peaks with respect to peaks falling within the exon regions that are not the first exon. C-E. ATAC-seq urostyle profiles at stage 56 (blue), stage 61 (red), and stage 65 (green) at the loci of validated up-regulatory genes narrowed down from RNA-seq analyses. 


\section{5 - REFERENCES}

705

706

707

708

709

710

711

712

713

714

715

716

717

718

719

720

721

722

723

724

725

726

727

728

729

730

731

732

733

734

735

736

737

738

739

740

741

742
Anders, S., P. T. Pyl, and W. Huber. 2015. 'HTSeq--a Python framework to work with highthroughput sequencing data', Bioinformatics, 31: 166-9.

Auxerre-Plantie, E., T. Nielsen, M. Grunert, O. Olejniczak, A. Perrot, C. Ozcelik, D. Harries, F. Matinmehr, C. Dos Remedios, C. Muhlfeld, T. Kraft, R. Bodmer, G. Vogler, and S. R. Sperling. 2020. 'Identification of MYOM2 as a candidate gene in hypertrophic cardiomyopathy and Tetralogy of Fallot, and its functional evaluation in the Drosophila heart', Dis Model Mech, 13.

Behr, R., C. Heneweer, C. Viebahn, H. W. Denker, and M. Thie. 2005. 'Epithelial-mesenchymal transition in colonies of rhesus monkey embryonic stem cells: a model for processes involved in gastrulation', Stem Cells, 23: 805-16.

Bianco, A. C., and R. R. da Conceicao. 2018. 'The Deiodinase Trio and Thyroid Hormone Signaling', Methods Mol Biol, 1801: 67-83.

Brachvogel, B., F. Zaucke, K. Dave, E. L. Norris, J. Stermann, M. Dayakli, M. Koch, J. J. Gorman, J. F. Bateman, and R. Wilson. 2013. 'Comparative proteomic analysis of normal and collagen IX null mouse cartilage reveals altered extracellular matrix composition and novel components of the collagen IX interactome', J Biol Chem, 288: 13481-92.

Branham, A. E., and J. C. List. 1979. 'Development of the Urostyle during Metamorphosis in 5 Species of Anurans', Journal of Morphology, 159: 311-29.

Bray, N. L., H. Pimentel, P. Melsted, and L. Pachter. 2016. 'Near-optimal probabilistic RNA-seq quantification', Nat Biotechnol, 34: 525-7.

Breeland, G., M. A. Sinkler, and R. G. Menezes. 2021. 'Embryology, Bone Ossification.' in, StatPearls (Treasure Island (FL)).

Brown, D. D., and L. Cai. 2007. 'Amphibian metamorphosis', Dev Biol, 306: 20-33.

Brown, D. D., Z. Wang, A. Kanamori, B. Eliceiri, J. D. Furlow, and R. Schwartzman. 1995. 'Amphibian metamorphosis: a complex program of gene expression changes controlled by the thyroid hormone', Recent Prog Horm Res, 50: 309-15.

Buenrostro, J. D., B. Wu, H. Y. Chang, and W. J. Greenleaf. 2015. 'ATAC-seq: A Method for Assaying Chromatin Accessibility Genome-Wide', Curr Protoc Mol Biol, 109: 2129 121299.

Callery, E. M., and R. P. Elinson. 2000. 'Thyroid hormone-dependent metamorphosis in a direct developing frog', Proc Natl Acad Sci U S A, 97: 2615-20.

Castaneda-Corral, G., J. M. Jimenez-Andrade, A. P. Bloom, R. N. Taylor, W. G. Mantyh, M. J. Kaczmarska, J. R. Ghilardi, and P. W. Mantyh. 2011. 'The majority of myelinated and unmyelinated sensory nerve fibers that innervate bone express the tropomyosin receptor kinase A', Neuroscience, 178: 196-207.

Chapman, D. L., A. Cooper-Morgan, Z. Harrelson, and V. E. Papaioannou. 2003. 'Critical role for Tbx6 in mesoderm specification in the mouse embryo', Mech Dev, 120: 837-47. 
766

767

768

769

770

771

772

773

774

775

776

777

778

779

780

781

782

783

784

Chen, J., S. B. Suo, P. P. L. Tam, J. D. J. Han, G. D. Peng, and N. H. Jing. 2017. 'Spatial transcriptomic analysis of cryosectioned tissue samples with Geo-seq', Nature Protocols, 12: $566-80$.

Chen, M., Y. Wu, H. Zhang, S. Li, J. Zhou, and J. Shen. 2020. 'The Roles of Embryonic Transcription Factor BRACHYURY in Tumorigenesis and Progression', Front Oncol, 10: 961.

Choi, J. H., S. S. Choi, E. S. Kim, M. P. Jedrychowski, Y. R. Yang, H. J. Jang, P. G. Suh, A. S. Banks, S. P. Gygi, and B. M. Spiegelman. 2014. 'Thrap3 docks on phosphoserine 273 of PPARgamma and controls diabetic gene programming', Genes Dev, 28: 2361-9.

Cleaver, O., and P. A. Krieg. 1998. 'VEGF mediates angioblast migration during development of the dorsal aorta in Xenopus', Development, 125: 3905-14.

Cleaver, O., D. W. Seufert, and P. A. Krieg. 2000. 'Endoderm patterning by the notochord: development of the hypochord in Xenopus', Development, 127: 869-79.

Cleaver, O., K. F. Tonissen, M. S. Saha, and P. A. Krieg. 1997. 'Neovascularization of the Xenopus embryo', Dev Dyn, 210: 66-77.

Corces, M. R., A. E. Trevino, E. G. Hamilton, P. G. Greenside, N. A. Sinnott-Armstrong, S. Vesuna, A. T. Satpathy, A. J. Rubin, K. S. Montine, B. Wu, A. Kathiria, S. W. Cho, M. R. Mumbach, A. C. Carter, M. Kasowski, L. A. Orloff, V. I. Risca, A. Kundaje, P. A. Khavari, T. J. Montine, W. J. Greenleaf, and H. Y. Chang. 2017. 'An improved ATACseq protocol reduces background and enables interrogation of frozen tissues', Nat Methods, 14: 959-62.

Cunliffe, V., and J. C. Smith. 1992. 'Ectopic mesoderm formation in Xenopus embryos caused by widespread expression of a Brachyury homologue', Nature, 358: 427-30.

- 1994. 'Specification of mesodermal pattern in Xenopus laevis by interactions between Brachyury, noggin and Xwnt-8', EMBO J, 13: 349-59.

Dong, H., Y. Zhang, J. Wang, D. S. Kim, H. Wu, B. Sjogren, W. Gao, L. Luttrell, and H. Wang. 2017. 'Regulator of $G$ protein signaling 2 is a key regulator of pancreatic beta-cell mass and function', Cell Death Dis, 8: e2821.

Fernando, R. I., M. Litzinger, P. Trono, D. H. Hamilton, J. Schlom, and C. Palena. 2010. 'The Tbox transcription factor Brachyury promotes epithelial-mesenchymal transition in human tumor cells', J Clin Invest, 120: 533-44.

Galis, F., and J. A. Metz. 2007. 'Evolutionary novelties: the making and breaking of pleiotropic constraints', Integr Comp Biol, 47: 409-19.

Gan, Z., L. Ding, C. J. Burckhardt, J. Lowery, A. Zaritsky, K. Sitterley, A. Mota, N. Costigliola, C. G. Starker, D. F. Voytas, J. Tytell, R. D. Goldman, and G. Danuser. 2016. 'Vimentin Intermediate Filaments Template Microtubule Networks to Enhance Persistence in Cell Polarity and Directed Migration', Cell Syst, 3: 500-01.

Gaspar, J. M. 2018. 'NGmerge: merging paired-end reads via novel empirically-derived models of sequencing errors', BMC Bioinformatics, 19: 536.

Gentsch, G. E., T. Spruce, R. S. Monteiro, N. D. L. Owens, S. R. Martin, and J. C. Smith. 2018. 'Innate Immune Response and Off-Target Mis-splicing Are Common MorpholinoInduced Side Effects in Xenopus', Dev Cell, 44: 597-610 e10. 
Ghebranious, N., R. D. Blank, C. L. Raggio, J. Staubli, E. McPherson, L. Ivacic, K. Rasmussen, F. S. Jacobsen, T. Faciszewski, J. K. Burmester, R. M. Pauli, O. Boachie-Adjei, I. Glurich, and P. F. Giampietro. 2008. 'A missense T (Brachyury) mutation contributes to vertebral malformations', J Bone Miner Res, 23: 1576-83.

Giacomazzi, G., B. Holvoet, S. Trenson, E. Caluwe, B. Kravic, H. Grosemans, A. CortesCalabuig, C. M. Deroose, D. Huylebroeck, S. Hashemolhosseini, S. Janssens, E. McNally, M. Quattrocelli, and M. Sampaolesi. 2017. 'MicroRNAs promote skeletal muscle differentiation of mesodermal iPSC-derived progenitors', Nat Commun, 8: 1249.

Gould, R. M., T. Oakley, J. V. Goldstone, J. C. Dugas, S. T. Brady, and A. Gow. 2008. 'Myelin sheaths are formed with proteins that originated in vertebrate lineages', Neuron Glia Biol, 4: $137-52$.

Handrigan, G. R., and R. J. Wassersug. 2007. 'The anuran Bauplan: a review of the adaptive, developmental, and genetic underpinnings of frog and tadpole morphology', Biological Reviews, 82: 1-25.

Hattori, T., C. Muller, S. Gebhard, E. Bauer, F. Pausch, B. Schlund, M. R. Bos1, A. Hess, C. Surmann-Schmitt, H. von der Mark, B. de Crombrugghe, and K. von der Mark. 2010. 'SOX9 is a major negative regulator of cartilage vascularization, bone marrow formation and endochondral ossification', Development, 137: 901-11.

Hayata, T., A. Eisaki, H. Kuroda, and M. Asashima. 1999. 'Expression of Brachyury-like T-box transcription factor, Xbra3 in Xenopus embryo', Dev Genes Evol, 209: 560-3.

Henderson, S. R., D. Guiliano, N. Presneau, S. McLean, R. Frow, S. Vujovic, J. Anderson, N. Sebire, J. Whelan, N. Athanasou, A. M. Flanagan, and C. Boshoff. 2005. 'A molecular map of mesenchymal tumors', Genome Biol, 6: R76.

Hessle, L., G. A. Stordalen, C. Wenglen, C. Petzold, E. Tanner, S. H. Brorson, E. S. Baekkevold, P. Onnerfjord, F. P. Reinholt, and D. Heinegard. 2014. 'The skeletal phenotype of chondroadherin deficient mice', PLoS One, 8: e63080.

Horowitz, M. 2003. 'Matrix proteins versus cytokines in the regulation of osteoblast function and bone formation', Calcified Tissue International, 72: 5-7.

Hotta, K., H. Takahashi, T. Asakura, B. Saitoh, N. Takatori, Y. Satou, and N. Satoh. 2000. 'Characterization of Brachyury-downstream notochord genes in the Ciona intestinalis embryo', Dev Biol, 224: 69-80.

Kanamori, A., and D. D. Brown. 1996. 'The analysis of complex developmental programmes: amphibian metamorphosis', Genes Cells, 1: 429-35.

Karsenty, G. 2008. 'Transcriptional control of skeletogenesis', Annual Review of Genomics and Human Genetics, 9: 183-96.

Kovalenko, E. E., and E. V. Anisimova. 1987. 'The Structural and Developmental Peculiarities in the Sacral-Urostyle Area of Anura', Zoologichesky Zhurnal, 66: 557-+.

Kovalenko, E. E., and I. G. Danilov. 2006. 'Diversity of the sacral-urostyle region in the family Bufonidae (Amphibia, Anura). 1. Actual diversity of sacrum in Bufonidae', Zoologichesky Zhurnal, 85: 500-16.

Langmead, B., and S. L. Salzberg. 2012. 'Fast gapped-read alignment with Bowtie 2', Nat Methods, 9: 357-9. 
Lofberg, J., and A. Collazo. 1997. 'Hypochord, an enigmatic embryonic structure: study of the axolotl embryo', Journal of Morphology, 232: 57-66.

Love, M. I., W. Huber, and S. Anders. 2014. 'Moderated estimation of fold change and dispersion for RNA-seq data with DESeq2', Genome Biol, 15: 550.

Mach, D. B., S. D. Rogers, M. C. Sabino, N. M. Luger, M. J. Schwei, J. D. Pomonis, C. P. Keyser, D. R. Clohisy, D. J. Adams, P. O'Leary, and P. W. Mantyh. 2002. 'Origins of skeletal pain: sensory and sympathetic innervation of the mouse femur', Neuroscience, 113: $155-66$.

Mackie, E. J., Y. A. Ahmed, L. Tatarczuch, K. S. Chen, and M. Mirams. 2008. 'Endochondral ossification: how cartilage is converted into bone in the developing skeleton', Int $J$ Biochem Cell Biol, 40: 46-62.

Magrini, E., A. Mantovani, and C. Garlanda. 2016. 'The Dual Complexity of PTX3 in Health and Disease: A Balancing Act?', Trends Mol Med, 22: 497-510.

Messenger, N. J., C. Kabitschke, R. Andrews, D. Grimmer, R. Nunez Miguel, T. L. Blundell, J. C. Smith, and F. C. Wardle. 2005. 'Functional specificity of the Xenopus T-domain protein Brachyury is conferred by its ability to interact with Smad1', Dev Cell, 8: 599610.

Mills, M., N. Yang, R. Weinberger, D. L. Vander Woude, A. H. Beggs, S. Easteal, and K. North. 2001. 'Differential expression of the actin-binding proteins, alpha-actinin-2 and -3 , in different species: implications for the evolution of functional redundancy', Hum Mol Genet, 10: 1335-46.

Ordway, G. A., A. Szebeni, M. M. Duffourc, S. Dessus-Babus, and K. Szebeni. 2009. 'Gene expression analyses of neurons, astrocytes, and oligodendrocytes isolated by laser capture microdissection from human brain: detrimental effects of laboratory humidity', $J$ Neurosci Res, 87: 2430-8.

Paraiso, K. D., I. L. Blitz, J. J. Zhou, and K. W. Y. Cho. 2019. 'Morpholinos Do Not Elicit an Innate Immune Response during Early Xenopus Embryogenesis', Dev Cell, 49: 643-50 e3.

Pickering, C., and J. Kiely. 2017. 'ACTN3: More than Just a Gene for Speed', Front Physiol, 8: 1080 .

Postma, A. V., M. Alders, M. Sylva, C. M. Bilardo, E. Pajkrt, R. R. van Rijn, S. Schulte-Merker, S. Bulk, S. Stefanovic, A. Ilgun, P. Barnett, M. M. Mannens, A. F. Moorman, R. J. Oostra, and M. C. van Maarle. 2014. 'Mutations in the T (brachyury) gene cause a novel syndrome consisting of sacral agenesis, abnormal ossification of the vertebral bodies and a persistent notochordal canal', J Med Genet, 51: 90-7.

Qin, X., Q. Jiang, K. Nagano, T. Moriishi, T. Miyazaki, H. Komori, K. Ito, K. V. Mark, C. Sakane, H. Kaneko, and T. Komori. 2020. 'Runx2 is essential for the transdifferentiation of chondrocytes into osteoblasts', PLoS Genet, 16: e1009169.

Radisky, D. C. 2005. 'Epithelial-mesenchymal transition', J Cell Sci, 118: 4325-6.

Rahman, M. M., I. S. Kim, D. Ahn, H. J. Tae, and B. Y. Park. 2020. 'PR domaincontaining protein 12 (prdm12) is a downstream target of the transcription factor zic1 during cellular 
differentiation in the central nervous system: PR domain containing protein is the right form', Int J Dev Neurosci, 80: 528-37.

Reul, J. M., and F. Holsboer. 2002. 'On the role of corticotropin-releasing hormone receptors in anxiety and depression', Dialogues Clin Neurosci, 4: 31-46.

Sanchez, R. S., and S. S. Sanchez. 2013. 'Characterization of pax1, pax9, and uncx sclerotomal genes during Xenopus laevis embryogenesis', Dev Dyn, 242: 572-9.

. 2015. 'Paraxis is required for somite morphogenesis and differentiation in Xenopus laevis', Dev Dyn, 244: 973-87.

Schiaffino, S., A. C. Rossi, V. Smerdu, L. A. Leinwand, and C. Reggiani. 2015. 'Developmental myosins: expression patterns and functional significance', Skelet Muscle, 5: 22.

Schulte-Merker, S., and J. C. Smith. 1995. 'Mesoderm formation in response to Brachyury requires FGF signalling', Curr Biol, 5: 62-7.

Senevirathne, G., S. Baumgart, N. Shubin, J. Hanken, and N. H. Shubin. 2020. 'Ontogeny of the anuran urostyle and the developmental context of evolutionary novelty', Proceedings of the National Academy of Sciences of the United States of America, 117: 3034-44.

Shen, X. K., Y. Hu, G. Q. Xu, W. Z. Chen, K. Xu, Q. C. Ran, P. P. Ma, Y. R. Zhang, J. H. Li, and K. Y. Cai. 2014. 'Regulation of the Biological Functions of Osteoblasts and Bone Formation by Zn-Incorporated Coating on Microrough Titanium', Acs Applied Materials \& Interfaces, 6: 16426-40.

Shook, D. R., C. Majer, and R. Keller. 2004. 'Pattern and morphogenesis of presumptive superficial mesoderm in two closely related species, Xenopus laevis and Xenopus tropicalis', Dev Biol, 270: 163-85.

Showell, C., O. Binder, and F. L. Conlon. 2004. 'T-box genes in early embryogenesis', Dev Dyn, 229: 201-18.

Shubin, N. H., and F. A. Jenkins. 1995. 'An Early Jurassic Jumping Frog', Nature, 377: 49-52.

Shubin, N., C. Tabin, and S. Carroll. 2009. 'Deep homology and the origins of evolutionary novelty', Nature, 457: 818-23.

Smith, J. C., B. M. Price, J. B. Green, D. Weigel, and B. G. Herrmann. 1991. 'Expression of a Xenopus homolog of Brachyury $(\mathrm{T})$ is an immediate-early response to mesoderm induction', Cell, 67: 79-87.

Snell, C. A. 2015. 'Identifying Ranid urostyle, ilial and anomolous bones from a 15 th century London well', Herpetological Journal, 25: 245-55.

Sodek, J., and M. D. McKee. 2000. 'Molecular and cellular biology of alveolar bone', Periodontology 2000, 24: 99-126.

Stein, G. S., J. B. Lian, J. L. Stein, A. J. van Wijnen, M. Montecino, J. Pratap, J. Choi, S. K. Zaidi, A. Javed, S. Gutierrez, K. Harrington, J. L. Shen, and D. Young. 2003. 'Intranuclear organization of RUNX transcriptional regulatory machinery in biological control of skeletogenesis and cancer', Blood Cells Molecules and Diseases, 30: 170-76.

Strauss, B., A. Harrison, P. A. Coelho, K. Yata, M. Zernicka-Goetz, and J. Pines. 2018. 'Cyclin B1 is essential for mitosis in mouse embryos, and its nuclear export sets the time for mitosis', J Cell Biol, 217: 179-93. 
Tarazona, O. A., L. A. Slota, D. H. Lopez, G. Zhang, and M. J. Cohn. 2016. 'The genetic program for cartilage development has deep homology within Bilateria', Nature, 533: 869.

Tigan, A. S., F. Bellutti, K. Kollmann, G. Tebb, and V. Sexl. 2016. 'CDK6-a review of the past and a glimpse into the future: from cell-cycle control to transcriptional regulation', Oncogene, 35: 3083-91.

Tomlinson, R. E., B. A. Christiansen, A. A. Giannone, and D. C. Genetos. 2020. 'The Role of Nerves in Skeletal Development, Adaptation, and Aging', Front Endocrinol (Lausanne), 11: 646.

Tschopp, P., and C. J. Tabin. 2017. 'Deep homology in the age of next-generation sequencing', Philos Trans R Soc Lond B Biol Sci, 372.

Uittenbogaard, M., K. K. Baxter, and A. Chiaramello. 2010. 'NeuroD6 genomic signature bridging neuronal differentiation to survival via the molecular chaperone network', $J$ Neurosci Res, 88: 33-54.

Velez-delValle, C., M. Marsch-Moreno, F. Castro-Munozledo, I. J. Galvan-Mendoza, and W. Kuri-Harcuch. 2016. 'Epithelial cell migration requires the interaction between the vimentin and keratin intermediate filaments', Sci Rep, 6: 24389.

Vujovic, S., S. Henderson, N. Presneau, E. Odell, T. S. Jacques, R. Tirabosco, C. Boshoff, and A. M. Flanagan. 2006. 'Brachyury, a crucial regulator of notochordal development, is a novel biomarker for chordomas', J Pathol, 209: 157-65.

Wagner, G. P. 2015. 'Evolutionary innovations and novelties: Let us get down to business!', Zoologischer Anzeiger, 256: 75-81.

Wan, Z., D. Jiang, S. Chen, J. Jiao, L. Ji, A. S. Shah, H. Wei, X. Yang, X. Li, Y. Wang, and J. Xiao. 2016. 'T-box transcription factor brachyury promotes tumor cell invasion and metastasis in non-small cell lung cancer via upregulation of matrix metalloproteinase 12', Oncol Rep, 36: 306-14.

Wang, S., L. Liu, J. Liu, W. Zhu, Y. Tanizaki, L. Fu, L. Bao, Y. B. Shi, and J. Jiang. 2019. 'Gene Expression Program Underlying Tail Resorption During Thyroid Hormone-Dependent Metamorphosis of the Ornamented Pygmy Frog Microhyla fissipes', Front Endocrinol (Lausanne), 10: 11.

Widmer, C., J. M. Gebauer, E. Brunstein, S. Rosenbaum, F. Zaucke, C. Drogemuller, T. Leeb, and U. Baumann. 2012. 'Molecular basis for the action of the collagen-specific chaperone Hsp47/SERPINH1 and its structure-specific client recognition', Proc Natl Acad Sci U S $A, 109: 13243-7$.

Yamaguchi, T., S. Kawakami, M. Hatamoto, H. Imachi, M. Takahashi, N. Araki, T. Yamaguchi, and K. Kubota. 2015. 'In situ DNA-hybridization chain reaction (HCR): a facilitated in situ HCR system for the detection of environmental microorganisms', Environ Microbiol, 17: 2532-41.

Yaoita, Y., and D. D. Brown. 1990. 'A correlation of thyroid hormone receptor gene expression with amphibian metamorphosis', Genes Dev, 4: 1917-24. 
Yasuoka, Y., C. Shinzato, and N. Satoh. 2016. 'The Mesoderm-Forming Gene brachyury Regulates Ectoderm-Endoderm Demarcation in the Coral Acropora digitifera', Curr Biol, 26: 2885-92.

Youlten, Scott E., John P. Kemp, John G. Logan, Elena J. Ghirardello, Claudio M. Sergio, Michael R. G. Dack, Siobhan E. Guilfoyle, Victoria D. Leitch, Natalie C. Butterfield, Davide Komla-Ebri, Ryan C. Chai, Alexander P. Corr, James T. Smith, Sindhu T. Mohanty, John A. Morris, Michelle M. McDonald, Julian M. W. Quinn, Amelia R. McGlade, Nenad Bartonicek, Matt Jansson, Konstantinos Hatzikotoulas, Melita D. Irving, Ana Beleza-Meireles, Fernando Rivadeneira, Emma Duncan, J. Brent Richards, David J. Adams, Christopher J. Lelliott, Robert Brink, Tri Giang Phan, John A. Eisman, David M. Evans, Eleftheria Zeggini, Paul A. Baldock, J. H. Duncan Bassett, Graham R. Williams, and Peter I. Croucher. 2021. 'Osteocyte transcriptome mapping identifies a molecular landscape controlling skeletal homeostasis and susceptibility to skeletal disease', Nature Communications, 12: 2444.

Youlten, Scott E., John P. Kemp, John G. Logan, Elena J. Ghirardello, Claudio M. Sergio, Michael R. G. Dack, Siobhan E. Guilfoyle, Victoria D. Leitch, Natalie C. Butterfield, Davide Komla-Ebri, Ryan C. Chai, Alexander P. Corr, James T. Smith, John A. Morris, Michelle M. McDonald, Julian M. W. Quinn, Amelia R. McGlade, Nenad Bartonicek, Matt Jansson, Konstantinos Hatzikotoulas, Melita D. Irving, Ana Beleza-Meireles, Fernando Rivadeneira, Emma Duncan, J. Brent Richards, David J. Adams, Christopher J. Lelliott, Robert Brink, Tri Giang Phan, John A. Eisman, David M. Evans, Eleftheria Zeggini, Paul A. Baldock, J. H. Duncan Bassett, Graham R. Williams, and Peter I. Croucher. 2020. 'Osteocyte Transcriptome Mapping Identifies a Molecular Landscape Controlling Skeletal Homeostasis and Susceptibility to Skeletal Disease', bioRxiv: 2020.04.20.051409.

Zhang, Y., T. Liu, C. A. Meyer, J. Eeckhoute, D. S. Johnson, B. E. Bernstein, C. Nusbaum, R. M. Myers, M. Brown, W. Li, and X. S. Liu. 2008. 'Model-based analysis of ChIP-Seq (MACS)', Genome Biol, 9: R137.

Zhao, L., L. Liu, S. Wang, H. Wang, and J. Jiang. 2016. 'Transcriptome profiles of metamorphosis in the ornamented pygmy frog Microhyla fissipes clarify the functions of thyroid hormone receptors in metamorphosis', Sci Rep, 6: 27310.

Zhu, J., K. M. Kwan, and S. Mackem. 2016. 'Putative oncogene Brachyury (T) is essential to specify cell fate but dispensable for notochord progenitor proliferation and EMT', Proc Natl Acad Sci US A, 113: 3820-5.

Zhu, Q., L. Song, G. Peng, N. Sun, J. Chen, T. Zhang, N. Sheng, W. Tang, C. Qian, Y. Qiao, K. Tang, J. D. Han, J. Li, and N. Jing. 2014. 'The transcription factor Pou3fl promotes neural fate commitment via activation of neural lineage genes and inhibition of external signaling pathways', Elife, 3 . 


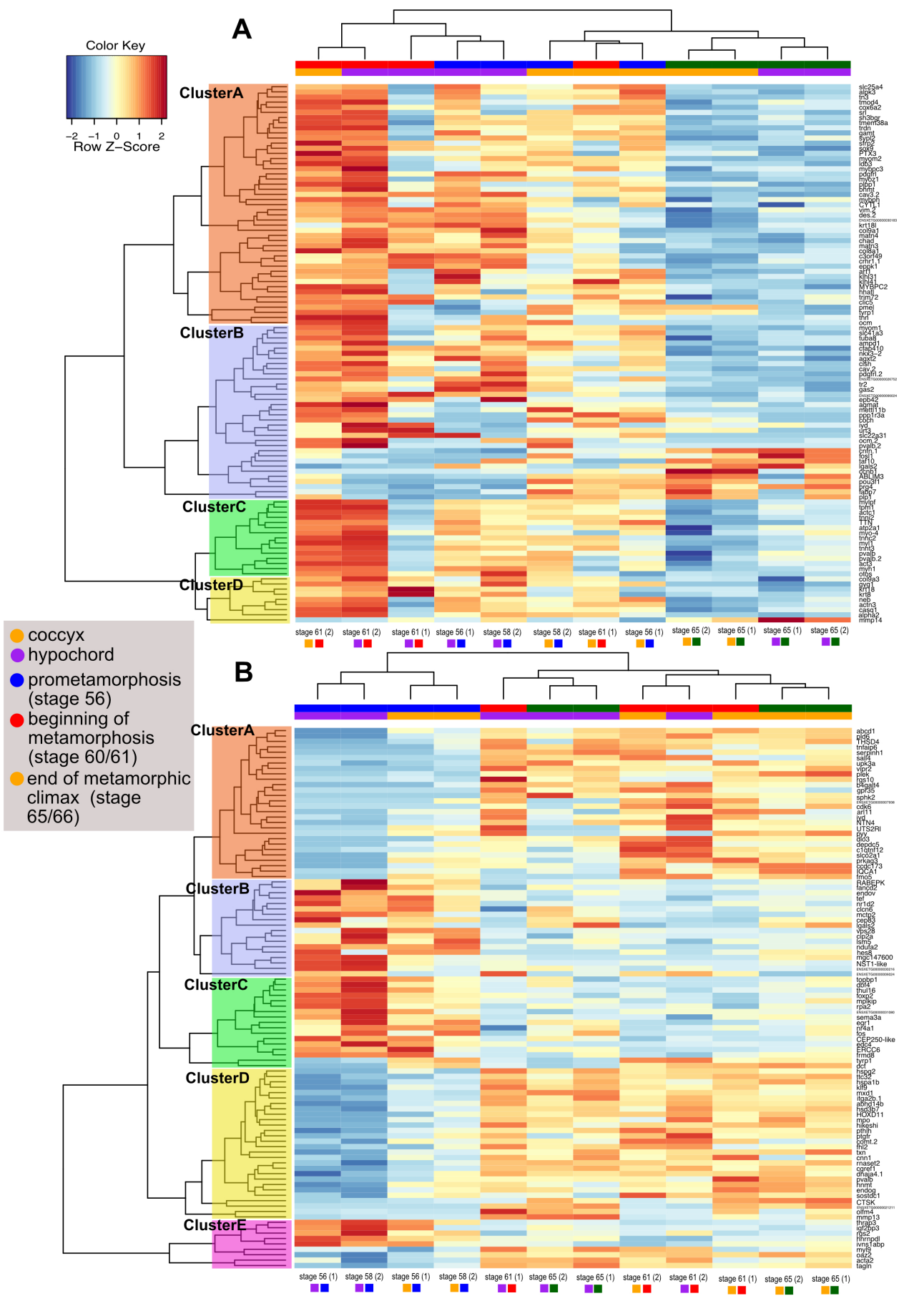

Figure S1:

Differentially expressed genes across different time points during urostyle development. A. Heatmap showing before and beginning of metamorphosis vs end of metamorphosis, indicating that there is a set of genes (eg., PTX3, SOX9, KRT18) that switch off at the end of metamorphosis in both tissue types. B. Heatmap comparing before and beginning of metamorphosis, highlighting a set of genes (eg., $D I O 3$, HOXD 11, PVALB) that switch on during urostyle development. Purple: coccyx; Yellow: hypochord; Blue: before metamorphosis; Red: beginning of metamorphosis; Green: end of Metamorphosis 
bioRxiv preprint doi: https://doi.org/10.1101/2021.10.04.462674; this version posted October 5, 2021. The copyright holder for this preprint (which was not certified by peer review) is the author/funder, who has granted bioRxiv a license to display the preprint in perpetuity. It is made available under aCC-BY-NC-ND 4.0 International license.

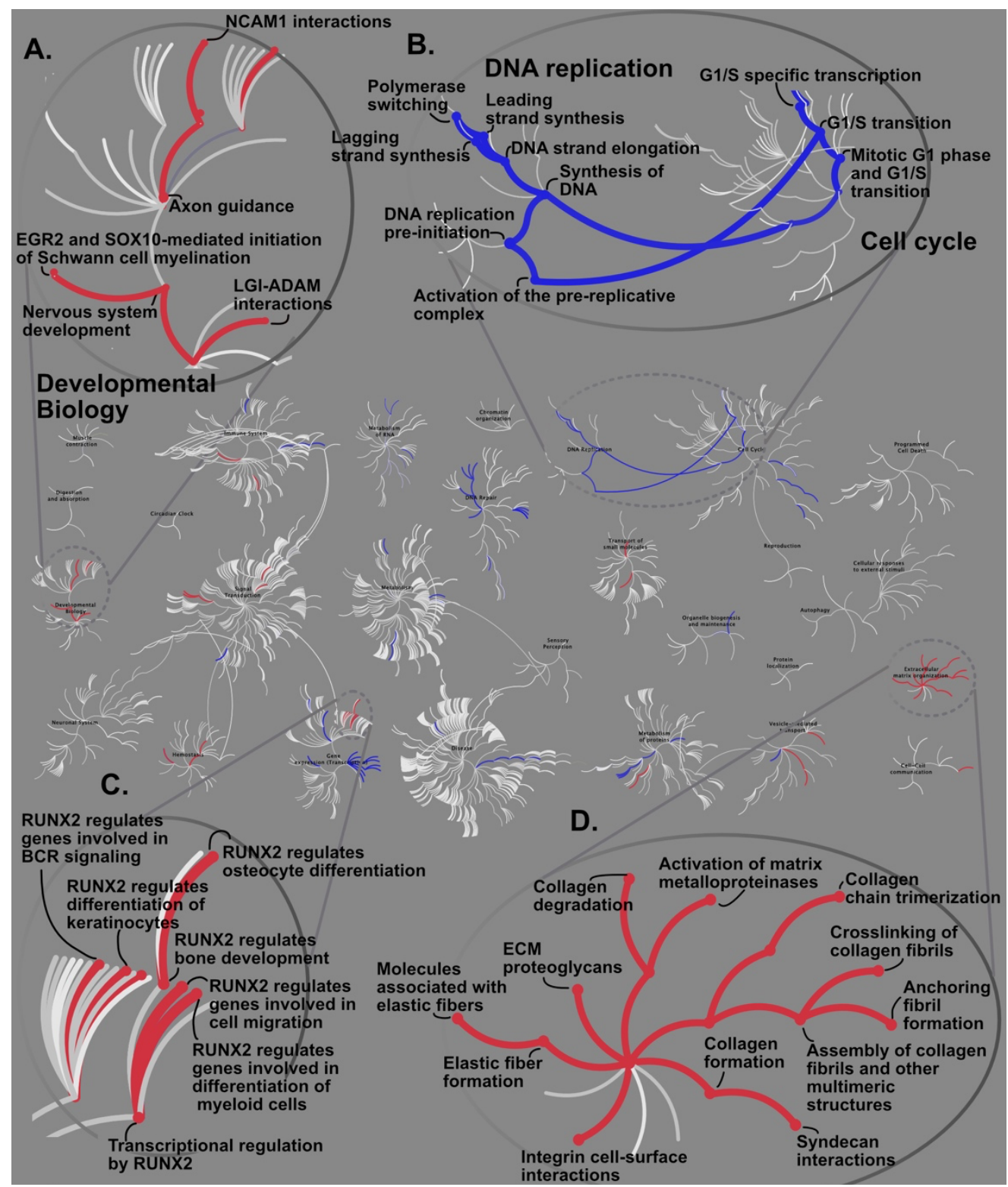

Figure S2: Reactome pathway analysis for up/down regulatory genes in two different time points: before metamorphosis (blue) and beginning of metamorphosis (red). The central circles represent a top-level pathway, and the circles away from the center represents lower levels in each respective pathway. Zoomed-in sections of top-level pathways of Developmental Biology (A), DNA replication and Cell cycle (B), Gene expression (C), and Extracellular matrix organization (D) are shown. Overrepresented pathways $(\mathrm{P}<0.05)$ are colored in blue (prometamorphosis) and red (beginning of metamorphosis). Pathways that are not significant are shown in light gray lines. 


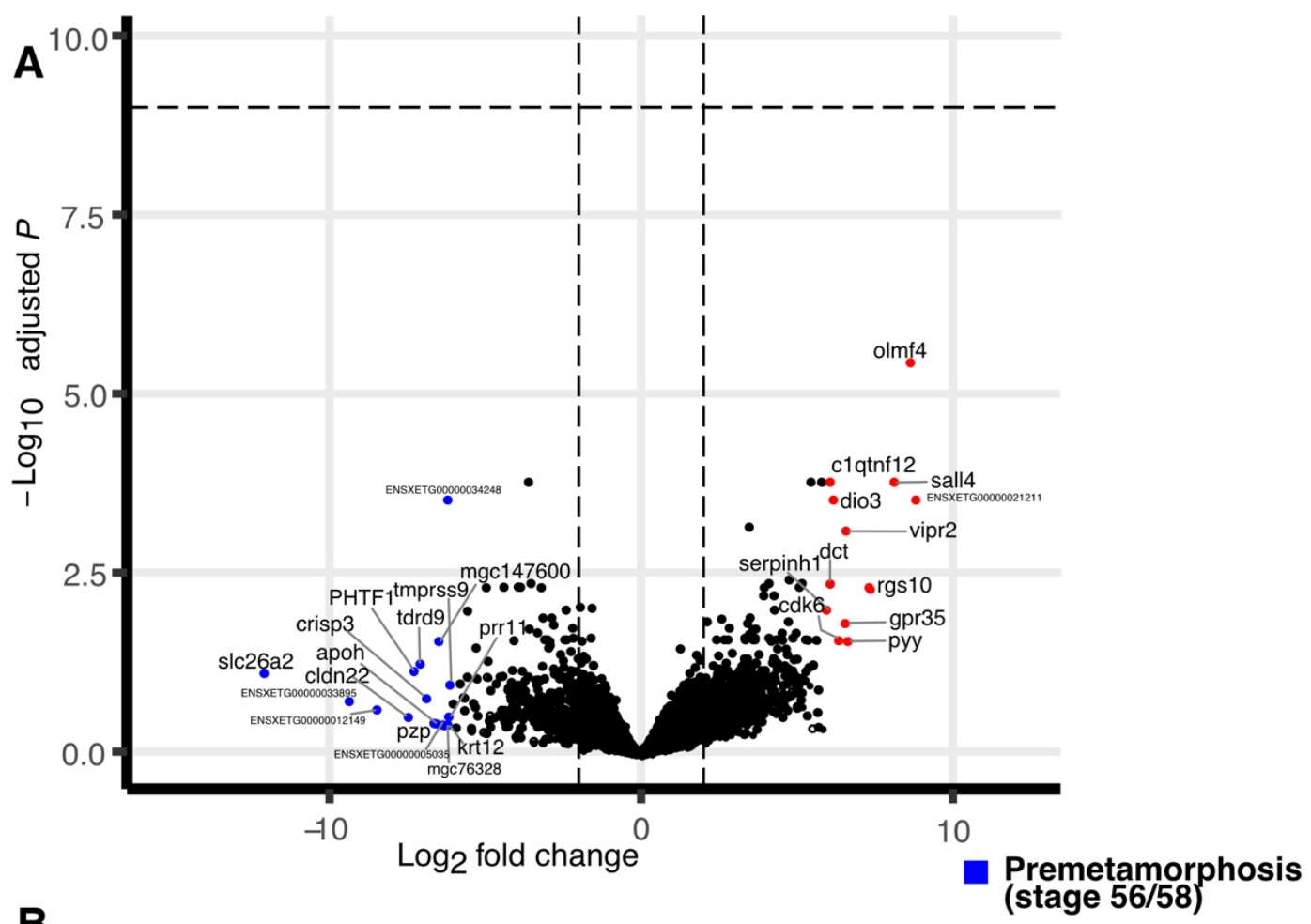

B

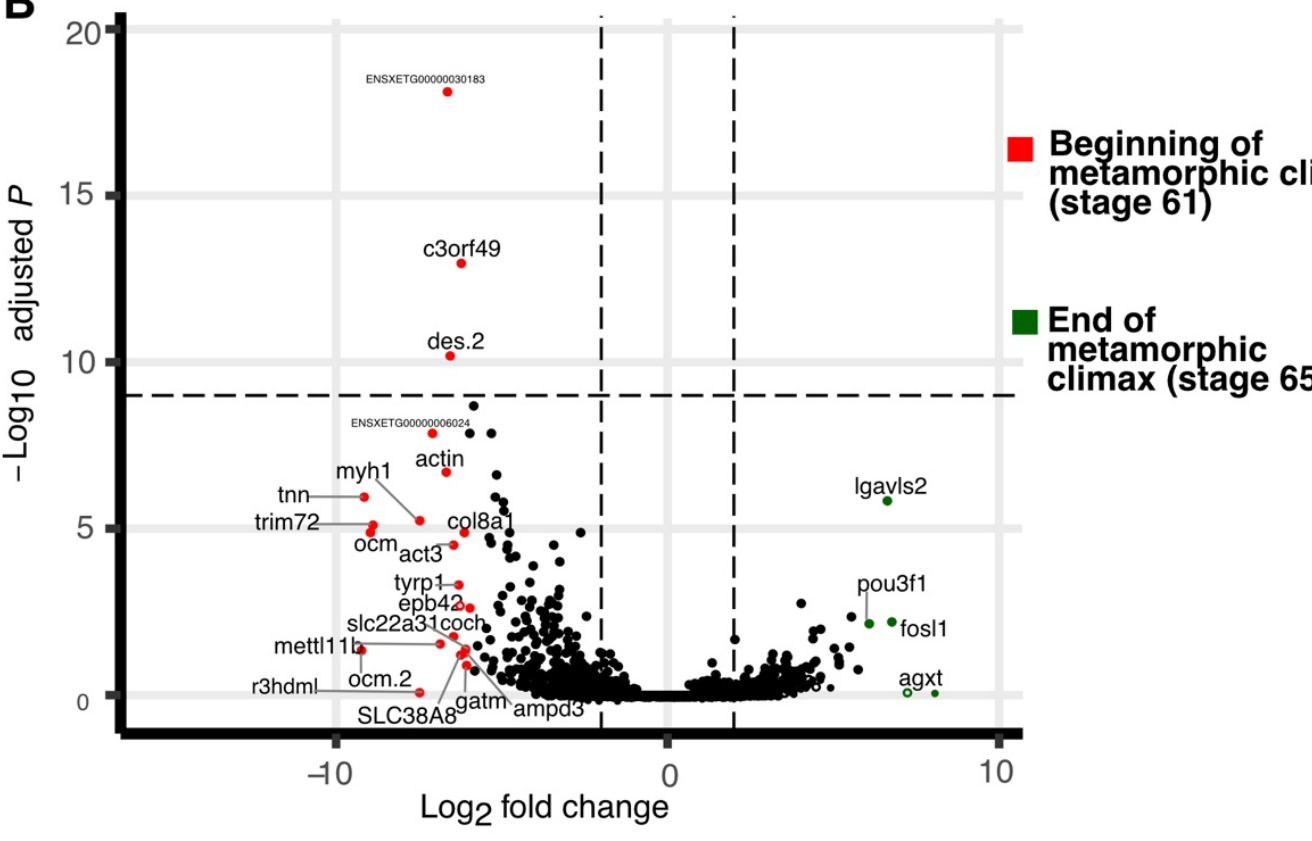

1070

1071

1072

1073
Figure S3: Volcano plot showing differentially expressed genes across three developmental time points, during the formation of the urostyle $(\mathrm{P}<0.05, \mathrm{FDR}<0.01)$. 
bioRxiv preprint doi: https://doi.org/10.1101/2021.10.04.462674; this version posted October 5, 2021. The copyright holder for this preprint (which was not certified by peer review) is the author/funder, who has granted bioRxiv a license to display the preprint in perpetuity. It is made available under aCC-BY-NC-ND 4.0 International license.

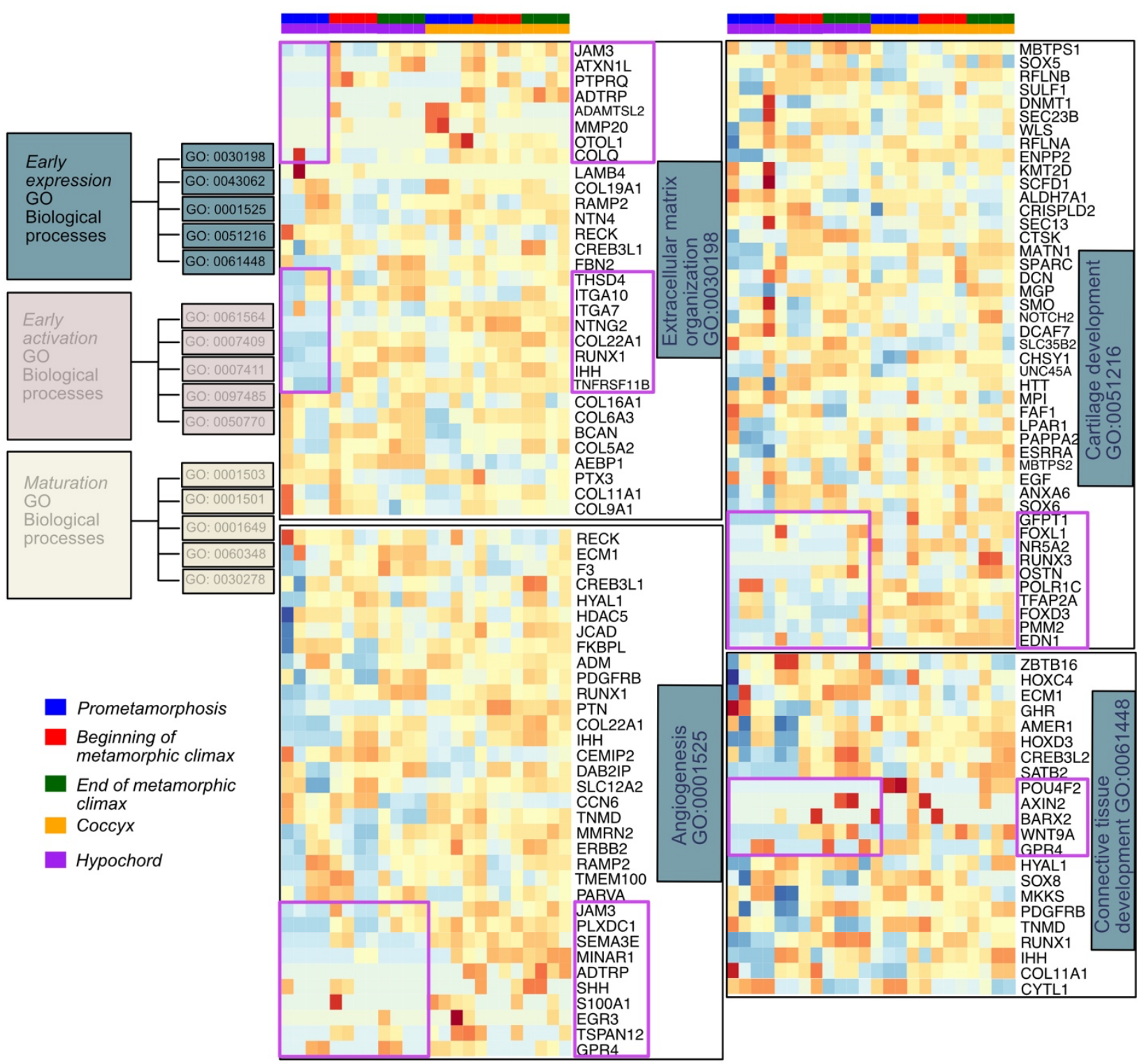

Figure S4: Heatmaps showing differentially expressed genes involved in GO functions belonging to the "Early expression cluster" of osteocyte differentiation. Significant genes of the osteocyte transcriptome are divided into three clusters (Youlten et al. 2021). This cluster includes the GO functions Extracellular matrix organization, Angiogenesis, Cartilage development, and Connective tissue development. Genes of interest that are differentially expressed between the coccyx and hypochord are highlighted in purple color. 

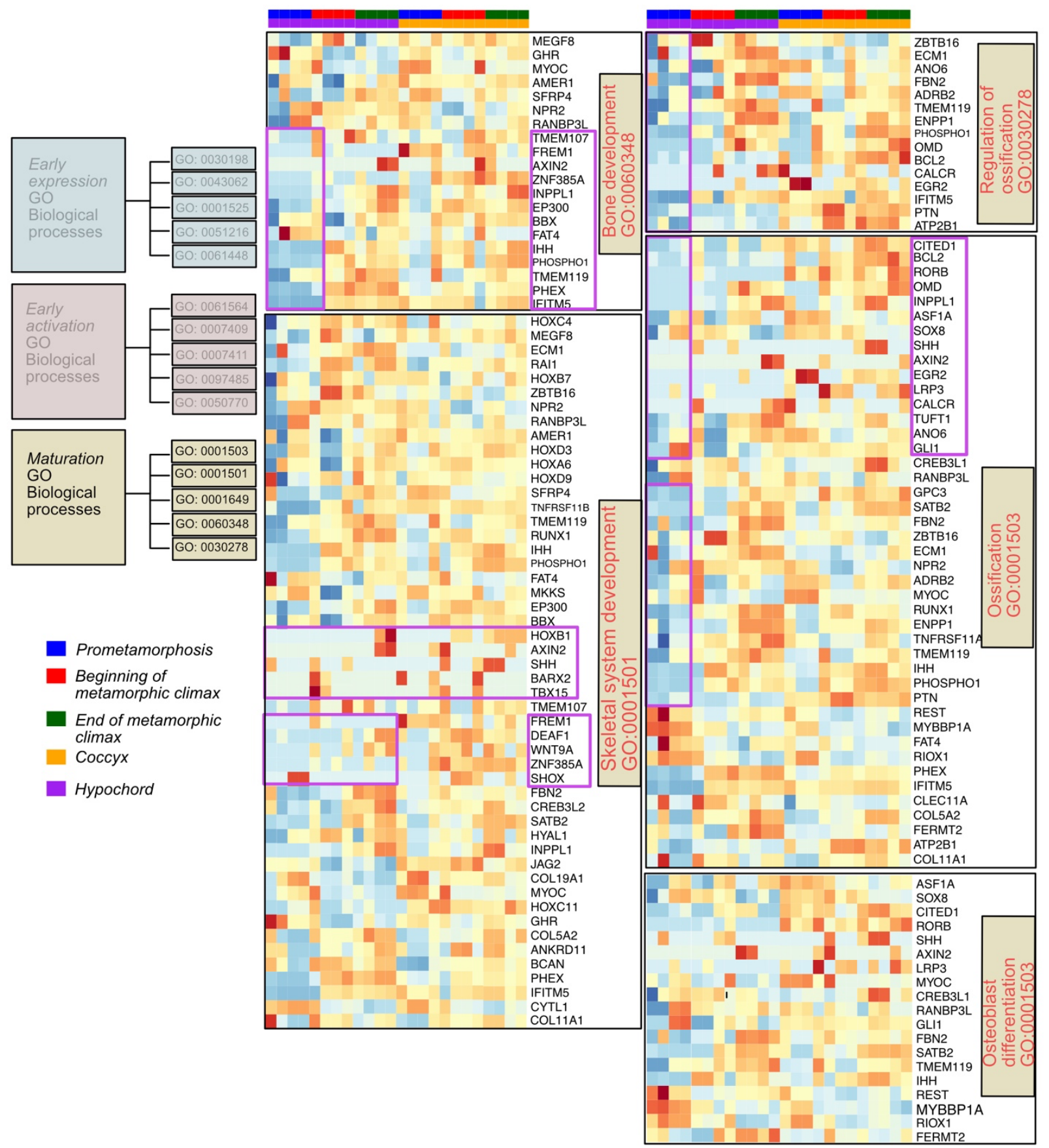

Figure S5: Heatmaps showing differentially expressed genes involved in GO functions belonging to the "Maturation cluster" of osteocyte differentiation. Significant genes of the osteocyte transcriptome are divided into three clusters (Youlten et al. 2021). This cluster includes the GO functions Bone development, Skeletal system development, Osteoblast differentiation, Ossification, and Regulation of ossification. Genes of interest that are differentially expressed between the coccyx and hypochord are highlighted in purple color. 